UNDERSTANDING THE EXPERIENCE OF OLDER CHINESE WOMEN WHOSE SOCIO-ECONOMIC STATUS CHANGED AFTER MIGRATION TO CANADA

\author{
By \\ Qi Mao, BSW, York University, Ontario, 2012 \\ A Major Research Paper \\ Presented to Ryerson University \\ in partial fulfillment of the requirements for the degree of \\ Master of Social Work \\ In the program of Social Work \\ Toronto, Ontario, Canada, 2014 \\ (C) Qi Mao 2014
}




\section{$\underline{\text { Author's Declaration }}$}

I hereby declare that I am the sole author of this major research paper.

I authorize Ryerson University to lead this paper to other institutions or individuals for the purpose of scholarly research.

Signature

I further authorize Ryerson University to reproduce this paper by photocopying or by other means, in total or in part, at the request of other institutions or individuals for the purpose of scholarly research.

Signature 


\title{
UNDERSTANDING THE EXPERIENCE OF OLDER CHINESE WOMEN WHOSE SOCIO-ECONOMIC STATUS CHANGED AFTER MIGRATION TO CANADA
}

\author{
(C) Qi Mao, 2014 \\ Mast of Social Work \\ Ryerson University
}

\begin{abstract}
This study explores the lived experiences of four elderly Chinese immigrant women in Toronto. Using a combination of the socialist feminist theory and an anti-oppressive theory as the framework, this study analyzes how these women's "dual role"- domestic labour and waged labour and the state pension policies cause them to live in poverty. The findings of this study indicate that these women lack power and are oppressed in almost every interaction that they have within the public sphere - the labour market and the private sphere - the home. Therefore, their poverty is far beyond their personal control. It is strongly associated with social structure injustice based on gender, class, race, immigrant status, age, and state policies.

The strategies developed by these women to deal with the oppressive environment and the challenges that they encounter enable them to regain a sense of comfort and connection so that they are empowered and are not feeling alone.
\end{abstract}

Key words: Elderly Chinese women, Poverty, Oppression, Discrimination, Marginalization 


\section{Acknowledgement:}

I would like to acknowledge and thank the four elderly Chinese immigrant women who participated in this research and shared their personal experiences with me. Without their contribution, this research would not have been possible.

I would also like to sincerely thank my supervisor Dr. Lisa Barnoff, for your encouragement, guidance and valuable feedback on this project as well as your endless patience in the past year. I cannot complete this thesis without your great support. My thanks also go out to Dr. Henry, Parada, who reviewed this work and provided thoughtful suggestions.

Finally, I would like to thank my family, my husband and my son. Your love, support, and encouragement were also important and invaluable. 


\section{Dedication}

I dedicate this research to the four elderly Chinese immigrant women who worked with me and shared their personal experiences regarding their lives after migration to Canada. This research is also dedicated to my parents. Thank you for your support and encouragement throughout my educational journey. 


\section{Table of contents}

Chapter I: Introduction............................................................... 1

Chapter II: Literature Review........................................................... 3

Chapter III: Theoretical Framework................................................. 19

Chapter VI: Research Design \& Methodology .........................................24

Chapter V: Findings.................................................................. 34

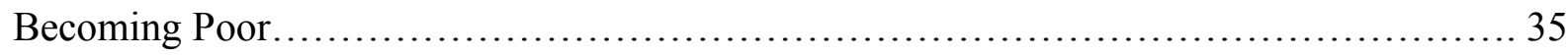

Foreign education not being accepted................................................... 37

Problem with employment........................................................... 40

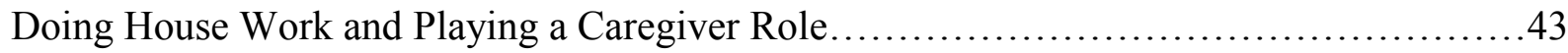

Elderly Chinese Immigrant Women's Mental Health....................................45

Talking with Family members and Trusted Friends .....................................47

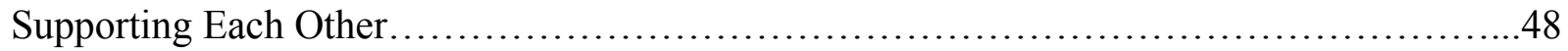

Chapter VI: Discussion...............................................................50

Elderly Chinese Immigrant Women and Powerless......................................51

Foreign Education Credentials....................................................... 52

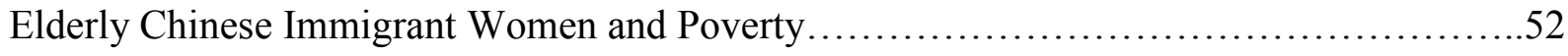

Elderly Chinese Immigrant Women and Mental health.................................54

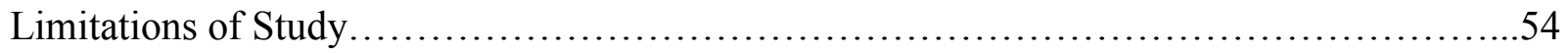

Chapter VII: Implications............................................................55

Chapter VIII: Conclusion.............................................................60

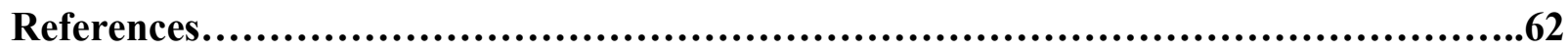

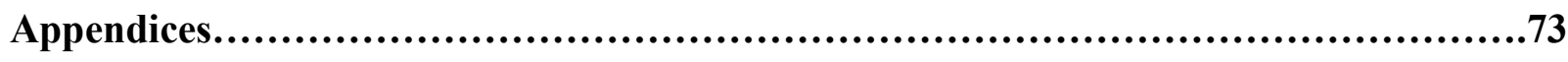




\section{List of Appendices}

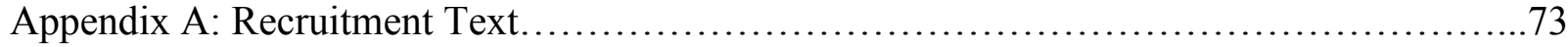

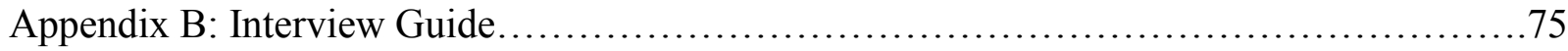

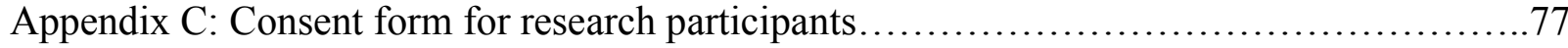




\section{CHAPTER I: INTRODUCTION}

\section{Social Location and Personal Interest}

Fitzgerald (2004) states that it is important to examine researchers' identities and their social locations in the research process because the power relationship between researchers and participants is often unequal. Carniol (2005) indicates that analysing our own social location is to better examine the social location of others. He further indicates that our world views are shaped by our identities and positions. Social location refers to our place in society. It is a key element to understand who we are, where we come from, and which community or social group we belong to. Social location also associates with race, gender, age, education, class, marital status, ability, religion, sexual orientation, geographic location and political view. I am an immigrant, a mother, a daughter, a social work student, and a Chinese Canadian. My various features construct my position in the world as well as impacting on how I see the world and how my relation interacts with the outside of myself. (Heron, 2005).

There are two factors which interest me in learning more about the experience of elderly immigrant women from China, particularly those recent arrivals. First, I am an immigrant and a woman from Mainland China. I have aging parents who are currently living in Beijing. Since my sister and I both live in Toronto and no other siblings in China, according to the Chinese government laws (the Marriage Law and the Protection of Rights and Interests of the Aged), children have an obligation to support their parents. That means children have a duty to visit their parents regularly, look after them, provide financial and emotional support and give consideration to their parents' special requirements (Yeung \& Xu, 2011). Although my parents are healthy and independent, in the future, they are more likely to come here to live with either me or my sister. Secondly, I learned gerontology after moving to Canada. In the past few years I 
have had opportunities to work with seniors in the community agency, long-term care facility and hospital settings. Some cases impressed me profoundly. For instance, an older couple in their 80s came to the agency I worked, for consultation about senior housing. Both of them were professionals prior to their retirement in China. The husband used to be an engineer and the wife was a high school teacher. They were sponsored by their daughter who is the only child they have and lived in her house. But they were planning to move out of the house because their future son-in-law did not want to live with them. In order to not affect their daughter's relationship with her fiancé, the old couple wanted to have their own place. However, based on their financial situation, it is obvious that they could not afford the high price of the housing market. They lived very frugally, in order to save some bus tickets they even walked to the agency from Yonge Street to Victoria Park Avenue. During the interview, I was aware that the husband also so worried about his wife's mental health because as he said, his wife used to be a talkative person but now he noted that she speaks less and less since they moved to Canada, sometimes even not saying a word for a whole day. Another case I experienced is a senior woman who was hospitalized due to her stroke. At the time of her discharge, the total money she had was only $\$ 40$. The cases I have experienced deeply touch me and influence my thinking toward the aging population. As a researcher, I constantly wonder how come these women who were once well-educated middle class professionals live in such hardship situation. What makes them so vulnerable to poverty? What are the underlying issues? How about Canadian pension policies and system toward immigrant seniors who come to Canada in their later-life? What life experiences do older Chinese immigrant women have after their socio-economic status changed significantly? With all these questions in mind, I started this research work. 
This research attempts to explore and understand the meaning of the lived experience of four elderly Chinese immigrant women who were experiencing the change of their socio-economic status and living in poverty. A qualitative research was chosen for this study as qualitative research values individual voices and lights up voices that have been marginalized. The research was guided by a combination of the socialist feminism and anti-oppressive theory to explore the lived experiences of these women by using a narrative approach to interviews that also incorporated phenomenological aspects. Through exploring themes emerged within the interviews with these Chinese women, the meaning of their lived experience was understood and the underlying issues related to their poverty were identified. Therefore, the marginalized voices of these women were brought out.

\section{CHAPTER II: LITERATURE REVIEW}

\section{Socio-economic status and quality of life in old age}

Socio-economic status is often measured as a combination of education, income, and occupation. It reflects a social standing of an individual or a group. Many research studies consistently suggest that socio-economic status is a key factor in determining an individual's quality of life. Previous literature has shown that people with high socioeconomic status who have higher levels of education, higher occupational status, and higher income are more likely to maintain independence and autonomy, enjoy quality of life, and feel life satisfaction and happiness in old age (Pinquart \& Sorensen, 2000; Novak \& Campbell, 2006; Bowling, 2005 ). Buchmann \& Hannum (2001) agree that education is a very important predictor of a person's socio-economic status as education can change an individual's occupational status and labour market participation. Nonetheless, compared with education, income is more directly an influence on quality of life and well-being in real life (Pinquart \& Sorensen, 2000). There is an evidence from 
previous literature that people are happier if they live with wealth rather than living in poverty (Bowling, 2005, Diener \& Biswas-Myers, 2002), and the level of happiness and life satisfaction increased along with increasing the level of income (Bowling, 2005; Veenhoven 1991; Heylighen \& Bernheim 2000).

In contrast, individuals with lower socioeconomic status in old age are more likely to experience economic stress (Yeung \& Xu, 2011, Bowling, 2005, Pinquart \& Sorensen, 2000), depend on families (Angel, Geum-Yong, \& Markides, 1999; Sanghera, 2010 ), have health issues (Yeung \& Xu, 2011; Lai, 2004) and live in poverty (NACA, 2005; Kaida \& Boyd, 2011).

Auger \& Tedford-Litle (2002) states in the past twenty years, the incomes of Canada's older population have improved significantly. According to the report of the National Seniors Council on Low Income Among Seniors (2011), between 1980 and 2006, the low income rate among seniors decreased dramatically. This decline is mainly attributed to the result of improved Canada's Public Pension Plans. Even so, poverty still exists (NACA, 2005; Auger \& TedfordLitle, 2002; Kaida \& Boyd, 2011). Researchers have found that recent immigrant seniors, particularly elderly women, are more likely to live in low-income situation and suffer from poverty (Auger \& Tedford-Litle, 2002; NACA, 2005; Kaida \& Boyd, 2011).

\section{Poverty among recent immigrant senior women in Canada}

According to Statistics Canada (2006), seniors, defined as individuals 65 years old and above, were 4.2 million in Canada. The number of seniors is projected to grow to $21.9 \%$ of the Canadian population in 2026 (Statistics Canada, 2006). Among them, old women make up a big percentage due to their life expectancy. However, "women are among the poorest groups in Canadian society"(Mullaly, 2007, p.161). According to Naiman (2008), a number of feminist theories believe that women's poverty is mainly attributed to gender inequality. Radical feminism 
see women as a subordinate and oppressed group are often controlled by men in patriarchy society. Unlike radical feminism, Marxism feminism believes that gender inequality is interconnected to class and rooted in "the change in power relationships between the sexes that arose with the development of class-based societies" (Naiman, 2008, p.287). Nonetheless, socialist feminism combines radical feminism and Marxism stressing women's poverty not only related to gender inequality but also related to class, race, age, socioeconomic, and state policy (Naiman, 2008).

According to Picot and Sweetman (2005), compared to the earlier immigrants and Canadianborn seniors of similar age and profile, older recent immigrant adults face more economic difficulties as they experience higher unemployment rates and lower earnings in terms of their employment. This situation for recent immigrant seniors has become prevalent (Kaida \& Boyd, 2011; NACA, 2005). Based on the data of Statistic Canada (2006), in 2000, the percentage of recent immigrant seniors with low income was more than four times greater than that of Canadian-born seniors. In addition, unemployment rates of recent immigrant seniors in 2001 were significantly high. A survey in 2003 found that $26 \%$ of recent immigrant seniors were in the lowest income, versus $15 \%$ of non-immigrant seniors and $12 \%$ of immigrant seniors who came to Canada before 1981. In 2006, about 30 per cent of immigrants aged 65 and older were living in households having incomes below Statistics Canada's Low Income Cut-Off (LICO) (Turcotte \& Schellenberg, 2007), a tool used by Statistics Canada to measure poverty and examine how it changes over the year.

A study conducted by Palameta (2004) indicated that immigrant seniors aged 65 and over are more vulnerable in terms of income. Seniors who came after the age of 50 would not have had enough time to accumulate wealth through labour market participation and to prepare for 
retirement in the form of home ownership and savings (Angel et al., 1999; the National Seniors Council on Low Income Among Seniors, 2011). Moreover, several studies have shown that seniors who have been in Canada less than 10 years would not be eligible for the Canada Pension Plan based on current government policies (Palameta, 2004; the report of the National Seniors Council on Low Income Among Seniors, 2011; Dempsey, 2005; Service Canada, 2012). It is evident from previous literature that women constitute almost $60 \%$ of the seniors population and a larger number of those live below Government of Canada low-income benchmark (Auger \& Tedford-Litle, 2002). According to Statistics Canada (2012), in 2007, 7.5\% of women and $17 \%$ of unattached women aged 65 and over lived below LICO. A study by Kaida \& Boyd (2011) state that elderly women who are not part of the mainstream, are from ethnic minorities, immigrant to Canada in later life, are more likely to fall below the poverty line (NACA, 2005; Kaida \& Boyd, 2011; Gazso, 2005, Shields et al, 2011, Angel et al. 1999). Immigrant senior women, especially those who are widowed, are even more likely to live in poverty (Palameta, 2004; Auger \& Tedford-Litle, 2002). Palameta (2004) stated that in the year 2000, among female immigrants aged 65 and over who lived alone and who landed in Canada recently, $71 \%$ were in a low-income situation. In contrast, this was the case for $42 \%$ of Canadian-born women living alone (Palameta, 2004). Camey(1992) suggested that social inequalities, injustice based on class, gender, race, and age and economic factors all contribute to poverty. Elderly immigrant women's income is often less than Canadian-born men, Canadian-born women, and immigrant men (Pilowsky \& Mor, 1990). They are more likely live at the bottom of society because they often have less power in terms of making decisions on their lives (Pilowsky, 1991). In a study on older Mexican immigrants in the United States, Angel et al. (1999) suggested that older Mexican immigrants are less likely than 
natives or earlier migrants to have a pension. They are often found to live in poverty and largely rely on their families in the economy. Similarly, in an article written by Sanghera (2010) on the Punjabi elderly immigrants, the author states that as sponsored immigrants, the Punjabi elderly women depend on their children not only socially but also financially. This dependence could be up to ten years. Lewin (2003) argued that socio-economic status of elderly is decided by government pension policies and state support. The state may provide universal old-age allowances to help elderly reduce poverty.

\section{Canada's pension system and elderly immigrant women}

Canadian seniors typically have three income sources including the Old Age Security (OAS), the Canada Pension Plan/Quebec Pension Plan (CPP/QPP) and private saving (Auger \& TedfordLitle, 2002; Sanghera, 2010; Novak \& Campbell, 2006). The OAS is a non-contributory pension provided to any Canadian citizen or legal resident aged 65 and older who has lived in Canada for 10 years or more after age 18 (Dempsey, 2005; Service Canada, 2012). The Guaranteed Income Supplement (GIS) as a supplement of the OAS provides to OAS recipients with limited income or no other income, depending on marital status and income (Service Canada, 2009). Based on the current government pension policies, like OAS, GIS recipients are also required to reside in Canada for ten years. The CPP is a pay-as-you-go plan, where the monthly amount received by seniors is dependent on the numbers of year worked and previous earning levels. In order to qualify for the full C/QPP benefits, one must contribute for 40 years (Kaida \& Boyd, 2011). Although Canadian employees and employers are mandated to contribute to this federal plan, in 2003, more than two thirds of Canadian seniors' main income was from government transfers OAS and GIS (NACA, 2005). The last type of retirement income, private savings, includes Registered Retirement Savings Plans (RRSPs), employer pension plans and investments. The 
amount received from the aforementioned sources of income varies and typically favours those who can afford to save and work (NACA, 2005).

Despite all these provisions of income security in old age, poverty among elderly immigrant women, particularly recent arrivals, is persistent (Angel et al., 1999; Novak \& Campbell, 2006). One factor that results in their greater incidence of low incomes is the inability of recent immigrants to meet the minimum qualifying requirements for old age benefits such as the CPP, OAS, and GIS (Statistic Canada, 2006). This places low-income immigrant seniors at a significant disadvantage because they are more likely to rely on social security as their main source of income. Moreover, immigrant senior women are more likely to have no source of financial aid other than government income assistance (Auger \& Tedford-Litle, 2002). According to Statistics Canada, in 2003 among 258,000 low-income seniors, 154,000 were women. Poverty in old age largely becomes a women's problem (Auger \& Tedford-Litle, 2002). It is evident from previous research studies that poverty may lead to a higher incidence of illness and mortality as well as the development of psychosocial problems (Pilowsky, 1991).

Issues related to poverty: elderly immigrant women's health, living arrangement, transportation, life style, and independence and autonomy

\section{Elderly immigrant women's health}

A study by Pérez (2002) indicated that generally immigrants are in better health than the Canadian-born population in the same age range when they came to Canada. However, their health status generally declines with the passage of time. According to Statistic Canada (2006), most immigrant seniors, especially recent immigrants, are at greater risk of suffering poorer health than non-immigrant seniors. In $2003,26 \%$ of recent immigrant seniors who were in the 
lowest income reported poor health. This is about twice the proportion of those in the highest income (Canadian Community Health Survey, 2003; Statistic Canada, 2006).

Past research studies have indicated that economic security is crucial to the health well-being of older adults. Researchers agree that poverty may cause the development of psychosocial problems such as stress and anxiety which may lead immigrant seniors to poor health (Moritz, Kasl \& Berkman, 1989), lower life satisfaction (Revicki \& Mitchell, 1990), and depression (Eaton, Muntaner, Bovasso, \& Smith, 2001). Clinical studies continuously show that stress is negatively associated with an individual's quality of life (Pedersen et al., 2006; Watari \& Brodbeck, 2004). People in lower socio-economic groups are known to be more likely to die earlier than those in higher socio-economic groups (Bassuk, Berkman, \& Amick, 2002). They also have higher stroke incidence (Avendano, et al., 2006) and lower health-related quality of life (Huguet, Kaplan, \& Feeny, 2008). Lai (2004) in his study about elderly women from Mainland China notes that stress caused by poverty is considered a major risk factor for declines in mental health among older people. Yeung \& Xu (2011) suggested that those at the lower levels of socioeconomic status are more likely to experience financial stress which may lead to higher mental distress. Moreover, mental distress directly impact on mortality risks.

Yeung \& Xu (2011) pointed out that the risk factors for seniors to make them vulnerable to stress may include age, gender, being widowed, being a minority member, having low-income, and having no pension. Previous research has demonstrated that recent immigrant women have a higher risk of mental illness than long-term immigrants and the Canadian-born population, especially those who migrated after age 65 (Spence \& Koehn, 2010). Often, they are less healthy physically and mentally (Wilkinson et al. 2004; Lai, 2011). There is a study which shows that among low income women, $61 \%$ report fair or poor health compared to $22 \%$ of women in the 
high income category. Lai (2011) pointed out that being female, having a higher level of education, and being less financially independent are often more vulnerable and experience further stress as they have more knowledge and are able to understand their economic situation. Moreover, since 2003, females have been more likely than males to report that most days were quite a bit or extremely stressful. This gender difference also held true in 2012 (Canadian Community Health Survey, 2012). Dean, Kolody \& Wood (1992) found that women who worry about financial inadequacy are at greater risk of depression and have significantly poorer mental and affective well-being. Newman et al (1998) revealed that women experience almost twice the rate of depression compared to men, which is $14.1 \%$ for women and $7.3 \%$ for men (Lai, 2000). Some research studies have shown that immigrant seniors who are from developing countries such as China, Mexico, and Korea etc. are more likely to experience mental health problems (Lai, 1995; Gee, 1999; Tran et al. 2000, Da \& Garcia, 2010). A study by Kim (2002) of Korean elderly immigrants in US found that Korean seniors experienced serious mental illness such as depression which has been largely attributed to numerous stressors, including a lack of financial resources, identity confusion, language barriers, and others. Similarly, a study by Lai (2004) of elderly Chinese also found that disadvantaged socio-economic status often leads elderly immigrants to be at risk to depression and other mental health problems. This is also applied to the recent elderly immigrants. Lai (2004) suggested that recent arrivals have more depressive symptoms than those who have lived in Canada for a longer period of time.

\section{Living arrangements}

Auger \& Tedford-Litle (2002) indicated that income plays an important role in determine living arrangements of seniors. Angel et al. (1999) stated that one who has adequate income can certainly decide where one wants to live or whether one can live alone. Like the general 
population, Canadian seniors have a higher proportion of independent living (Statistic Canada, 2006; Kaida \& Boyd, 2011), especially seniors who are from Northern Western European countries are more likely to live with their spouse or live alone. However, researchers have also found that one of the significant distinguishing characteristics between the recent immigrant seniors and the long-term immigrant or Canadian-born seniors is that the recent immigrant seniors regardless men or women are much less likely to live alone (Boyd,1991). In contrast, most of them live in multigenerational households (Statistic Canada, 2006; Yeung \& Xu, 2011; Portes \& Rumbaut, 1990). One explanation of this situation is that many recent immigrant seniors who are sponsored by members of their family are more likely in disadvantaged socioeconomic situations (Sanghera, 2010). Thus, living with their families can possibly escape poverty (Chesley \& Poppie, 2009; Picot, Lu, \& Hou, 2009). In fact, a study by Rendall and Speare (1995) of immigrant seniors in the United States has shown that co-residence with families can reduced 42 per cent elderly poverty.

In addition, Kaida \& Boyd (2011) notes that living arrangements among seniors also associate with cultural preferences. They state that seniors from cultures that highlight family values are more likely to live with their children. However, seniors from cultures that emphasize an individual's privacy are likely to live alone. Nonetheless, evidence from a study on Mexican seniors by Angel et. al. (1999) shows that co-residence with family is a strategy to cope with economic constraint. Some studies have revealed that immigrant seniors from Asia, Mexico, and Central America have a higher rate of living with their adult children (Angel et al., 1999; Da \& Garcia, 2010; Mehr, 2013). Most of them also provide domestic work such as child care and household work so that their children are able to enter labor market, thus enhancing the economic wellbeing of a household (Angel \& Tienda, 1982). 
Angel et al. (1999) found that Mexican seniors in the United States are more likely to live with their children and financially depend on them. Angel \& Angel (1992) indicated that there is an unarguable factor that families are often the only resource for the seniors to turn for help. Thus, it seems that there is no option for the immigrant elderly to live alone due to their poor socioeconomic profiles (Sanghera, 2010; Angel et al., 1999; Da \& Garcia, 2010), and the needs of the older individual for economic support often mean that they remain dependent on the family. For immigrant seniors, Kaida and Boyd (2011) indicated that both cultural preferences and economic constraints influence their living arrangements. However, researchers agree that income and living arrangements are directly associated with quality of life for older adults. According to Da \& Garcia (2010), Ginsberg's (2006) study of elderly immigrants from the former Soviet Union suggested that living arrangements of seniors may have a significant impact on their quality of life.

\section{Transportation and participation in social activities}

Unlike the long-term immigrants and the native-born seniors who are fortunate enough to have financial resources to own cars, most immigrants who came to Canada in their later life often encounter economic constraints, cannot afford a car, and do not drive. They cannot get around by themselves without public transit (Da \& Garcia, 2010). In fact, most of them depend on their children for providing transportation (Sanghera, 2010). Previous literature has shown that economic constraints, language barriers, and lack of accessing affordable public transportation are the major factors that impact immigrant seniors' participation on social activities and independence. Sanghera (2010) pointed out that immigrant seniors are more likely dependent upon their children to meet their needs. This may include money, living arrangements, transportation and so on. For seniors with poor socio-economic status and without any social 
security support, the cost of riding the public transit in Canada is not cheap and most of recent immigrant seniors cannot afford it. In the study on Punjabi seniors, Sanghera (2010) suggested that all immigrant seniors should get a free bus pass. Likewise, Da \& Garcia (2010) pointed out that free public transportation (bus and subway) should be available to elderly immigrants in Canada because many countries in the world, such as England, China, and Australia have provided a much lower rate or free of charge public transportation to elderly population. The lack of accessing affordable public transportation and the higher cost of bus tickets would limit the mobility of seniors and impact on their participation in social activities. It may also diminish seniors' social network and increase their isolation (Auger \& Tedford-Litle, 2002; Da \& Garcia, 2010; Sanghera, 2010) as participation in social activities can maintain social relationship, avoid dependency, keep a sense of control over one's life, and enhance quality of life to older adults (Novak \& Campbell, 2006; Auger \& Tedford-Litle, 2002).

\section{Income and life style}

Income certainly affects lifestyle in old age (Bowling, 2005). Some studies have shown that the level of income over one's life can impact the type of food consumed, clothing, housing, leisure activities, and opportunities across life (Bowling, 2005). Low-income definitely affects everyone, but older immigrants are often more vulnerable living in disadvantaged socio-economic situations (Cutler et al., 2002; Lai, 2010). They struggle everyday because of inadequate incomes and because of insufficient social security support (Bowling, 2005). Several studies have shown that older immigrant women with low socio-economic status may have difficulty paying for their basic daily needs such as food and utilities. Some may have to consume leftover food, sew clothes, grow their own vegetable, and buy food at reduced prices (Yeung \& Hofferth 1998; Lai, 2010; Fenge et al,, 2012). A study by Yeung \& Xu (2011) of Chinese seniors found that some 
seniors limited their fruit intake so as to spend less in day-to-day living. Moreover, past studies have shown that in order to conserve money, some seniors would turn down the heat, eating at home rather than going out to eat with family and friends (Chappell \& Badger 1989; Cutler et al. 2002, Lai, 2010).

Bowling (2005) states that older adults value freedom and dislike being dependent on others for help, even the help from their children, however, poor immigrant seniors may face more barriers (Sanghera, 2010; Angel et al., 1999). Often they have to rely on their adult children due to inadequate financial resources and language barriers. Even though some seniors used to be professionals and have post-secondary education in their original countries (Sanghera, 2010). Bowling (2005) notes that seniors with low-income rarely have money to enjoy leisure activities in later life. In contrast, those with higher income can have adequate financial resources to be used to enhance their activities in old age. Bowling (2005) stated that for seniors who are in disadvantage socio-economic status, old age and economic constrains often make them feel a sense of powerlessness and loss of control. However, the ability to achieve independence and control over one's life is essential for an individual's autonomy. It is evident from previous literature that a lack of autonomy may lead to seniors in poor health conditions (Hemingway \& Marmot, 1999; Bowling, 2005). Growing research studies have demonstrated that people with lower socio-economic status are more likely than those in higher status to experience low levels of self-esteem and self-efficacy (Bowling, 2005). Furthermore, older people with low-income are more likely to limit their freedom to express what they want (Bowling, 2005). Several studies have revealed that for immigrant seniors, lack of independence and autonomy means taking quality away from their lives. In other words, independence and autonomy are strongly related to the level of income from pension, accumulated savings, and resources that immigrant seniors 
have. For instance, the abilities to afford the public transportation fees can play an important role for elderly on their continued independence (Bowling, 2005).

\section{Chinese immigrants in Canada}

Chinese immigration to Canada can be traced back to 1858 (Li, 2010). Initially Chinese migrations to Canada were from the United States in response to the gold rush in British Columbia. During the time of the Canadian Pacific Railway construction, most Chinese as cheap labour came to Canada directly from China ( $\mathrm{Li}, 2010)$. Once the railway construction was completed, the Canadian government introduced severe racial immigration restrictions against Chinese immigrants, such as the "head-tax" and the 1923 Exclusion Act (Yee, 1987). Based on these racial and discriminatory immigration policies, Chinese men were not allowed to bring their wives and families to Canada. Therefore, there were few Chinese women in Canada before 1950 (Yee, 1987). This situation was changed till 1967; the Canadian government introduced the "point system" of Immigration Act which focused on selecting immigrants based on their education and economic status. As a result, many professionals and skilled workers mainly from Mainland Chinese began arriving in Canada (Wang \& Lo, 2004). According to the 2006 census, the Chinese are a large ethno-racial group in Canada (Wang \& Lo, 2004). Between 1996 and 2001, the Chinese Canadian population increased significantly about 20 percent (Li, 2008). From 1998 till 2007, each year there were 33,443 new immigrants from China to Canada ( $\mathrm{Li}$, 2010). In 2006, Ontario became the largest Chinese community among all Canadian provinces with nearly 644,000 Chinese Canadians. British Columbia was the second with about 432,000 Chinese Canadians. Most live in urban areas. (Li, 2008). Far from being a homogenous group (Guo \& Devoretz, 2006), Chinese immigrants also come from Hong Kong, Taiwan, Vietnam and elsewhere in Asia and the West Indies. 
The population of elderly Chinese is also the fastest growing among all Canadian visible minority groups (Lai, 2004). In 1996, Chinese seniors are about $27 \%$ of the visible minority population (Statistics Canada, 2006). Moreover, in 2004, the aging Chinese population account for $10 \%$ of the total Chinese Canadian population. This is a 50\% increase from 1996 (Lai \& Leonenko, 2007). Among them, Chinese elderly women in Canada are slightly more than Chinese elderly men. According to Statistics Canada (2006), in 2001, 54\% of people aged 65 and over of Chinese origin were women. Most Chinese elderly live in metropolitan areas such as Toronto, Vancouver, and Montreal. Between 1991 and 2001, 46\% Chinese seniors lived in Toronto and 22\% in Vancouver (Statistics Canada, 2006). For the Toronto Census Metropolitan Area (CMA), the Chinese population over the age of 65 total approximately 32,000 ( $7 \%$ of all seniors), the majority of whom (97\%) are immigrants and slightly more than half $(56 \%)$ are women (Statistics Canada, 2006).

\section{Economic constraint}

Spence \& Koehn (2010) in their study shows that elderly Chinese women, particularly recent arrivals, are more likely in a disadvantaged socio-economic situation. They often do not have adequate financial resources in Canada and more likely to lack OAS/GIS, C/QPPs, as well as retirement pensions than the Canadian-born (Spence \& Koehn, 2010). A study by Wang (1997) of Chinese immigrant women has revealed that Chinese women are unable to get similar jobs they had in their original country. Some have to work in low-paid part-time jobs because their credentials are not recognized in Canada. Spence \& Koehn (2010) argue that these conditions lead the women's socio-economic status to decline. They experience economic constraint and are more likely to live in poverty. Social inequalities, injustice based on gender, race, class, age, and economic status all contribute to poverty (Wang, 1997). A study by Wang \& Lo (2004) of 
Chinese immigrants found that Chinese seniors have an extremely low total income, which was about $\$ 4,321$. Similarly, a study by Lai (2010) of Chinese elderly confirmed Wang \& Lo's study that $17.3 \%$ of the elderly Chinese from Mainland China lived on a monthly income less than $\$ 500$ which is below the Low Income Cut-off, an amount considered as quite insufficient according to the Canadian standard. In addition, Wang \& Lo (2004) indicate that Chinese seniors have a higher self-employment rate; this may reflect that they still needed to work for a living due to insufficient savings and pensions.

\section{Living with adult children and playing a caregiver role}

There is evidence from previous literature that most elderly Chinese immigrant women live with their children upon arriving in Canada (Mehr, 2013; Da \& Garcia, 2010; Kaida \& Boyd, 2011). Kaida and Boyd (2011) in their study on ethnic-racial older adults stated that economic constraint is the major factor that influences living arrangements among the Chinese elderly in Canada because co-residence with family can save money and prevent poverty (Kaida \& Boyd, 2011). Moreover, several research studies have found that the majority elderly Chinese women provide grandchildren care and help household work while living in their children's place (Spence \& Koehn, 2010; Mehr, 2013; Da \& Garcia, 2010). A study by Da \& Garcia (2010) of older Chinese immigrants has revealed that the need for taking care of grandchildren as requested by their children seems a strong reason for elderly Chinese women immigration to Canada.

\section{Transportation}

Like immigrants from other ethnic groups, most elderly Chinese women neither own a car nor drive. Compared to the public transportation in China, many think the fare of the public transit in Canada is quite high because public transportation in China is free of charge to seniors (Da \& 
Garcia, 2010). A number of studies have shown that Chinese elderly mainly depend on their children in providing transportations because most cannot afford the high cost of bus tickets based on their financial situation. Spence \& Koehn (2010) have reported that a Chinese woman, 58-year old, came to Canada eight years ago under the family category, is still dependent on her children and lives in her children's house. Even though she has university education and worked as an engineer in China, she could not find a professional job in Canada. In order to supplement the family income, she has to work as a part-time staff in a corner store. With her inadequate earnings and no subsidized bus pass, the senior woman finds it is difficult to travel in the city she lives.

\section{Elderly Chinese women's mental health}

Despite the economic constraints and the impact on living arrangement and transportation, mental health of older immigrant women from Mainland China has been highlighted in reviewed literature. The prevalence of depression among older Chinese immigrant women has been identified and is twice that of the general elderly population in Canada (Lai, 2004; Lai \& Chau, 2007; Spence \& Koehn, 2010). Lai (2004) in his study also found that elderly Chinese women in Canada show more serious depressive symptoms than Chinese men. Similarly, a study by Chow (2010) of elderly Chinese women in the United States affirmed that Chinese seniors had depressive symptoms. Wang (1997) suggested that the loss of social support, economic and social status and gender inequality are major stressors leading to depression of Chinese immigrant women.

Therefore, elderly immigrants, particularly elderly women who are from ethnic minorities and immigrant to Canada in their later life are more vulnerable to poverty (NACA, 2005; Kaida \& Boyd, 2011; Gazso, 2005, Shields et al, 2011) and suffer from depression. Like other ethnic 
older immigrants, older Chinese immigrant women not only bear low income (Wang \& Lo, 2005) but also have higher rates of depressive symptoms compared with those from the general population (Lai, 2004). However, previous studies only discussed the pieces of the issues on older Chinese immigrant women. It does not go further to examine the nature of the relationship between socio-economic status such as income and education and their lives in old age, especially whether changes of socio-economic status impact their everyday lives in the host country. Further, older Chinese women are often described in previous studies as having less education, lower professional status, and lower income (Uhlenberg \& Miner, 1996; Lai, 2004), there is little research being conducted so far that study the experience of older Chinese immigrant women who have relatively higher education and professional careers prior to their retirement in China and came to Canada recently to unite with their adult children. Therefore, the purpose of this research is to fill the gap, to understand the experience of the older Chinese women whose socio-economic status changed dramatically after immigrating to Canada, and to bring their voice out. The findings of this research might be important for policymakers, social service providers, and social work practitioners to understand the experience of older Chinese immigrant women and to develop strategies to address their concerns. It will make a contribution to social work practice with diverse elderly population.

\section{CHAPTER III: THEORETICAL FRAMEWORK}

\section{Introduction}

Applying appropriate theoretical frameworks for studies on older Chinese immigrant women is challenging because many theories are not able to analyze their multiple roles and identities. Hamilton (1996) suggests that the socialist feminist theory is an appropriate framework to investigate the experiences of elderly immigrant women. In this chapter, I explain 
the theoretical framework I utilized in pursuing my objective of understanding social factors that affect the lives of elderly Chinese immigrant women in Canadian society. I discuss the conceptual framework for this study includes socialist feminist theory (Naiman, 2008; Hamilton, 1996) and anti-oppressive theory (Young, 1990). Socialist feminist theory directly analyzes the lived experiences of older Chinese immigrant women and the anti-oppressive theory speaks to societal oppression of older Chinese immigrant status in the capitalist society.

\section{Socialist feminist and anti-oppressive theories}

Using socialist feminism and anti-oppressive theoretical lens, this research aims to recognize the various elements of power and oppression which influence recent elderly Chinese immigrant women's socio-economic status; in addition to understanding how the influences impact the women's lived experience in Canada, socialist feminism approaches reach beyond radical feminism emphasising patriarchy and Marxism focusing on capitalism, it "attempts to explain gender inequality by combining insights from both radical feminism and Marxism" (Naiman, 2008, p. 336). In this framework, power is linked to gender and class. Anti-oppressive approaches that highlight oppression are structural and systemic inequalities that certain groups are privileged and put at an advantage at the expense of other groups (Young, 1990). It is a social control system that distributes power along a hierarchy based on socially assigned identities (Gelderloos, 2005). Chinese immigrant women as an oppressed group are systematically discriminated, exploited, and marginalized due to their identities as women, immigrants, and visible minorities. They often have less power and are controlled by men in capitalist society (Naiman, 2008, Mullaly, 2007).

The use of socialist feminism and anti-oppressive approaches acknowledges that the deterioration of the economic status of elderly Chinese immigrant women and their poverty is 
constructed by social and economic injustice based on gender, class, and race as well as the state policy (Hamilton, 1996). It also serves to acknowledge that elderly Chinese women suffer multiforms of oppression which perpetuate the women's inequality. Using these two theoretical perspectives as the lens of analysis allows for the silenced voices of elderly Chinese immigrant women to be heard and recapture the lost knowledge of women of colour (Smith, 2013). A socialist feminist approach places a critical way of looking at the world and questioning why immigrant women are at great risk of poverty than men (Naiman, 2008). Socialist feminists reject radical feminism's claim that patriarchy is the primary source of women's poverty and oppression. Rather, they see women's poverty largely attributes to gender and class inequalities as intrinsic in capitalist system, which makes huge profits off women's unpaid labour at the home and underpaid labour in the workforce (Naiman, 2008). In drawing on the socialist feminist notion, Chinese immigrant women's dual role - domestic labour and wage labour - that the women combine in their everyday lives need be analyzed (Mullaly, 2007; Naiman, 2008). In the labour market, elderly Chinese immigrant women are more likely unemployed or work in unskilled, low-paying, and none unionized part-time jobs (Wang, 2009; Naiman, 2008). In addition, their domestic work which typically favourites men and children is often unnoticed and unvalued. These reflect capitalism's exploitation and women's powerlessness which makes the Chinese women as a group generally have less income than men and live in disadvantaged socioeconomic situation. Through this approach, the oppressions and the power inequalities both in the labour market and the home, the women's experiences, are identified.

A socialist feminist standpoint challenges what is assumed as taken for granted "knowledge" and how the "knowledge" is interpreted as feminists believe that power can produce knowledge (Fitzgerald, 2004). Fitzgerald (2004) argues that there is a danger that the voice of particular 
groups or particular forms of knowledge is silenced by dominant power. To disrupt the power inequalities (Hunter 2002), other forms of knowledge must be allowed and legitimated (Fitzgerald, 2004). This means the elderly Chinese immigrant women are the "knower" (Olesen, 2005) of their lived experience; their knowledge which is associated with their experiences, beliefs, values, cultures, and needs must be acknowledged (Fitzgerald, 2004). By this approach, the lost knowledge which is related to the reality of the women's lives can be recaptured and their life experiences in the new country can be understood.

Unlike socialist feminism, considering women's oppression is primarily caused by sexism and classism, anti-oppressive theory believes that oppression can be presented in multiple forms and levels which include but also go beyond structure oppression (Healy, 2005; Mullaly, 2007). Based on this theory, elderly Chinese immigrant women's oppression is not only associated with sexism in labour division in capitalist society, but also associated with racism, classism, ageism, and state policies resulting in discrimination, exploitation, marginalization in the dominant systems, the social structure, and the power that operated in their daily lives.

To challenge the oppressions that the Chinese women encounter and resist "the dominant order" (Mullaly, 2007, p.332), Healy (2005) suggests that an anti-oppressive approaches must be employed as the core concept of AOP is equality, justice, and non-discrimination (Healy, 2005). Since oppression is not a single form, understanding multiple layers of oppression and recognizing that all oppression is harmful and interact with each other will assist in illuminating the lived experience of participants for this study. In addition, as anti-oppressive social workers, we have to understand how oppression has been socially constructed, produced and reproduced systematically as well in everyday social processes and practices (Mullaly, 2007). 
An anti-oppressive approach requests that state policies should be equal and fair to all people regardless their gender, race, class, and age. However, the current Canadian retirement income system is designed to reward men, married, and support the rich while penalizing women, immigrants, visible minorities and single, separated or divorced individuals. Thus, the OAS, GIS, $\mathrm{C} / \mathrm{QPP}$ and the private occupational pension plans need to be re-evaluated because it is not equal and fair to recently arrived immigrant seniors. According to Healy (2005), as anti-oppressive social workers, we place the value of social justice in center in all dimension of our social work practice. In this sense, we do not blame the elderly Chinese immigrant women for their poverty. In contrast, we adopt a multidimensional analysis which recognizes the oppression they have experienced and the effects of social structural on their lives.

To challenge the dominant power relations and the status quo as well as to empower the women, this research is to value the Chinese women's experiences, to consider their voices and perspectives, and to advocate for a social structure changes (Fitzgerald, 2004, Harvey, 1990). Within the research process, the researcher tried to reduce power inequalities between the researcher and the researched so as to produce equally shared knowledge (Fitzgerald, 2004) as the purpose of this study is to understand the experiences of elderly Chinese immigrant women whose socio-economic status changed after immigrating to Canada. I believe that socialist feminism and anti-oppressive theories are appropriate choice because they recapture the lost knowledge of elderly Chinese immigrant women. In respect to this study, the elderly Chinese women are the experts of their issues because they have legitimate live experience on poverty and depression. Therefore, their experiences with oppressive consequence are viewed as knowledge, reality and truth that reflect the issues of women's poverty and depression in old age. 


\section{CHAPTER IV: RESEARCH DESIGN and METHODOLOGY \\ Research design}

For the purpose of this study, elderly Chinese immigrant women are defined as women from 6080 who were from Mainland China, spoke Mandarin, had resided in Canada less than 10 years, had post-secondary education or a university degree, and used to work as professionals prior to coming to Canada. This study used a qualitative design. A qualitative design was chosen because this study is attempting to explore and understand the meaning of the lived experiences of elderly Chinese immigrant women who were experiencing the change of their socio-economic status and living in poverty. This qualitative research explores the lived experiences of participants using a narrative approach that also incorporated phenomenological aspects. The conceptual framework for this study is a combination of socialist feminist theory and anti-oppressive theory. Perl \& Noldon (2000) states that qualitative research valued individual voices and was used to light up voices that have been marginalized; it stresses that there was no single reality; reality based upon individuals' perceptions and experiences within a given situation (Guido, et al., 2010; Perl \& Noldon, 2000). In addition, qualitative research investigates and explores complex issues by talking directly with participants and allowing them to tell their stories. Unlike quantitative research focusing on measuring and testing hypothesis, qualitative research aims to understand, interpret, and find meaning from the stories shared by the participants. In this sense, qualitative research is more responsive, inclusive, flexible, and diverse than those of quantitative research (Carter \& Little, 2007). In collaboration with that, this study also employs a phenomenological approach. 


\section{Phenomenology}

Phenomenology is designed to gain a deeper understanding of people's life experiences, especially how they perceive, feel, describe, and talk about a phenomenon (Smith, 2013; Creswell, 2007). Phenomenological approach focuses on not only individuals' subjective experiences, but also on how they interpret the world (Bogdan \& Biklen, 2007). It acknowledges that our personal experiences have meaning. In order to understand the meaning of the lived experiences of elderly Chinese immigrant women whose socio-economic status changed after migration to Canada, a phenomenological approach to this research is applied. This approach complements the narrative approach to interviews as analysis of their stories will be based on an attempt to understand their world and the meaning they attach to themselves. This approach elicits rich and descriptive data (Creswell, 2007) which not only explores the Chinese women's lived experience but also explores what meaning the women interpret to their experiences. Wang \& Lo (2004) emphasize the importance in understanding elderly Chinese immigrant women in poverty as a phenomenon. Phenomenology is utilized throughout the research of this paper. This approach conceptualizes Chinese immigrant women in poverty as a structural and social issue. Creswell (2007) defines "a phenomenological study describes the meaning for several individuals of their lived experiences of a concept or a phenomenon" (p.57). This approach also allows for a socialist feminist and anti-oppressive framework approach because it lets participants describe and identify the phenomenon based on their lived experience. Moustakas's transcendental phenomenology is chosen for this study as transcendental phenomenology "is focused less on the interpretations of the researcher and more on a description of the experiences of participants" (Cresswell, 2007, p.59). In this sense, the researcher will set aside her own experiences as much as possible to take a new perspective 
toward the phenomenon under examination in order to understand participants' lived experienced (Cresswell, 2007). Therefore, phenomenology is an appropriate approach to use as it allows elderly Chinese immigrant women in poverty as a phenomenon being identified and examined. It also complements the core concepts of socialist feminism that women are exploited, oppressed, and marginalized because of their identities and "due role" they play and antioppressive practice on social justice. This approach thereby suspends past knowledge and experience to understand a phenomenon at a deeper level (Cresswell, 2007). It also provides participants an opportunity to challenge any previous assumptions that may exist about the women's lived experiences.

Phenomenological approach supports the researcher developing a textural description (what participants experienced), a structural description (how they experienced a phenomenon in terms of the conditions, situations or context) and a combination of the textural description and structural description to convey an overall essence of the experience (Cresswell, 2007). The narrative approach "focuses on the stories told by individuals" (Cresswell, 2007, p. 54). Using the narrative approach allows elderly Chinese immigrant women's lived experiences to be expressed through their own words and perspectives. Bogdan and Biklen (2007) note that feminist approaches "emphasize the lived experience of the narrator and how that related to the intersection of gender, race, and social class" (p.57). Narrative approach also has been shown well fit within a social justice framework (Combs \& Freedman, 2012). Therefore, a narrative approach to interviews seems an appropriate approach. Through qualitative narrative approaches, the lived experiences of these women and how they encounter inequality based on gender, class, and race as well as oppressions will be explored. A post-modern paradigm will be presented through narrative research methodologies that will focus on women centred approaches that 
recognize multiple realities through participants responds (Crewell, 2009). A phenomenology approach in the analysis of the findings will "reduce individual experiences with a phenomenon to a description of the universal essence" (Crewell, 2007, p.58). This helps to understand that women's poverty and oppression are systemic inequality based on gender, class, and race in capitalist society. Application of critical theory through this research will also help in challenging traditional approaches to providing support for these women through formal intervention. The conceptual framework for this study, a combination of socialist feminist theory and anti-oppressive theory is used as a lens for data analysis. The combination of the theories facilitates the researcher's understanding of gender, class, and race for elderly Chinese immigrant women in the new country. This methodology evolves contextually as it responds to the lived realities that are encountered (Cresswell, 2009) by the women.

\section{Methodology}

After approval from the Research Ethic and Board of Ryerson University, the researcher recruited participants through the assistance of the New Canadian Community Centre (NCCC). The organization was selected because it is a Chinese based community agency which was established in 2001 and mainly provides settlement services to immigrants from Mainland China in the Greater Toronto area. The relationship between the agency and the researcher was a work relationship. The agency only provided assistance in recruitment of participants; the researcher conducted the research independently. This study was also separated from the service of the agency. In order to recruit the sample for the study, an invitation with information about the study was sent via electronic mail to NCCC. The researcher also met the program director of the agency, explained the purpose of the research, told the voluntary nature of the project, and provided information about the study by means of print-out materials (see Appendix A). 
Potential participants were from the clients of the agency. The agency staff distributed the materials to their clients and informed them that participation was voluntary based on their interest in the project. In the recruitment materials, the researcher also made it very clear that participation was voluntary and won't affect an individual's receipt of services at the organization. Clients who were not interested in the project were not pressured or affected receiving their services as the study is separate from the services of the agency. The researcher told staff to give people her contact information. Potential participants who were interested in participating in this study were encouraged to contact the researcher directly rather than staff at the agency who called on their behalf. Participation was confidential as the researcher spoke to staff involved in the recruitment process about confidentiality and not disclosing to others who the participants in the study were. When a potential participant expressed interest in the project, the researcher followed up with a phone call and ensured the potential participant met the criteria for eligibility. Four participants who were interested in the research, met the eligibility criteria, and resided in the great Toronto area completed the interview and were recruited for this study through the assistance of NCCC. All participants were provided translated documents (see Appendix C), including an information letter about this study, interview questions, and consent form from English to Chinese (and back-translated for accuracy). Consent forms were provided prior to the scheduled interview so that participants would have time to review it and to ask any questions they might have regarding this study. The consent form provided a description of the study, what would be done with the study, how to use the data, how confidentiality would be maintained. Oral explanations about the project were also provided to participants at the beginning of the interviews. The consent form was signed by participants at the interview. Consent for digital recording of the interviews was also obtained from four participants. All participants were 
notified that their participation was voluntary based on their interest in the project. They could stop or withdraw participation from the study at any point and if they chose to, their information would then be deleted. The researcher had aimed to interview three to five women for the nature of this study and was successful in being able to recruit four women. Since the sample size for this study was four participants, this study was not aiming to represent elderly Chinese immigrant women in general; it was only used as a pilot study focusing on understanding the lived experiences of elderly Chinese immigrant whose socio-economic status changed after migration to Canada.

One-on-one in-depth interviews were conducted with four participants between July and August, 2013. The researcher asked participants guiding questions to facilitate conversations and narratives about their lived experiences as an elderly immigrant woman whose socio-economic status changed. The researcher also took notes during the interview to capture any distinct statements by the participants. Smith (2013) emphasizes that interview notes allowed the researcher to monitor the process of data collection as well as to begin analyzing the information itself. Interviews were about 1 to 1.5 hour long and occurred only once. All participants were encouraged to request additional interviews if they felt the need, but none of the participants made such a request. Semi-structured narrative questions were used to understand participants' lived experiences. The following nine questions presented to participants were designed to explore understanding the lived experience of these women and the challenges they face.

1. How do the elderly Chinese women see their socio-economic status both in China and Canada? 
2. How do older Chinese immigrant women describe their life experiences in the host country?

3. What have the elderly Chinese women experienced in terms of the changes of their socioeconomic status?

4. What does it mean to be an elderly Chinese immigrant woman in a capitalist country?

5. What social policies may affect the women's lived experience?

6. Whether level of education of the elderly Chinese women have played an important role in their later life?

7. What factors do the elderly Chinese women think may affect their quality of life?

8. How do the elderly Chinese women view socio-economic status and their health?

9. How do older Chinese immigrant women cope with the challenges?

Upon completion of the interviews, the field notes were typed and saved on a computer for later analysis. Once the interviews were completed and all the data had been collected, precautions were taken to protect the original data, including password protecting the data files and keeping all raw data and back-up files in a locked desk drawer. Digital recording of interviews were collected and transcribed. Transcripts were analyzed to determine the emergent themes based on the theoretical framework of the study.

\section{Participants}

In order to protect the confidentiality of participants, the researcher was aware that it was her responsibility to protect the participants by maintaining anonymity. To ensure that, all names had been altered to protect the confidentiality of each participant, the researcher used pseudonyms instead of the participant's actual names. None of the detail reported would allow these women to be distinguishable. The names selected for each participant were decided randomly by the 
researcher herself. Four elderly Chinese immigrant women participated in this study. Participant ages ranged between 63 and 68, all participants were in permanent residence status and sponsored by their children. Four Participants identified themselves in low-come status and had experienced stress and depressive symptoms after migration to Canada. Of the sample, two (50\%) worked as university teachers prior to migration, one (25\%) worked as a high school teacher, and one $(25 \%)$ worked as a nurse. Of the sample, three $(75 \%)$ held bachelor degree; one $(25 \%)$ was with a college diploma. Two (50\%) were widows. However, marital status was not a determining factor in this research. The following is a brief profile of each participant based on information they shared during the interviews.

\section{$\mathrm{Li}$}

$\mathrm{Li}$ is a 64 year old married woman with a university degree from Tianjin, China. She states that she was an associate professor at a university prior to her retirement. She came to Canada under the family reunion category and was sponsored by her son. She tried to continue her career to teach students but she could not find any jobs in her professional field. She states that she has lived with her son's family (her son, daughter-in-law, and a two-year-old granddaughter) in an apartment in Toronto for 5 years since she moved to Canada. She helped taking care of her granddaughter and doing house works. She felt that her socio-economic status declined, particularly her economic status as she has to rely on her son's support both socially and economically.

Han

Han is a 63 year old married woman with a college diploma from Jiangsu province, China. Prior to her move to Canada, she was a nurse working on care management at a local hospital. She states that she lived independently in China. Upon immigrating to Canada, she had neither any 
chance to practice nursing nor lived alone. She has lived with her daughter for 4 years since she first arrived here. She provided babysitting to her grandchildren and the kids of her daughter's friend so that she could earn little money. She states that she really wanted to live by herself but her financial situation did not allow her to do so. She thought that the deterioration of her socioeconomic status was due to being unable to be employed and her previous education and work experience not recognized in the new country. She indicates that this leads to her economic insufficient and dependence on her daughter.

Chen

Chen is a 68 year old widow with a university degree from Shenyang, China. She used to be a high school teacher in China. She states that she applied to various kinds of jobs upon arrival in Canada, but either no reply or being rejected. She has been living with her daughter's family for 9 years since she moved to Canada. She states that she helped her daughter take care of her grandchildren, cook meals, and did some yard work. She notices that even though she has passed 65-year old, she is unable to access the OAS as she does not meet the 10 years residence requirement. She wishes that she could have enough pensions so that she could live independently without everything relying on her daughter.

Wang

Wang is a 67 year old widow with a university degree. She states that she worked at a university as a senior lecturer in China prior to her retirement. She was sponsored by her son to Canada and has lived with her son's family for 9 years. She thought that her socio-economic status declined significantly as she did not have enough income and her pension is small after converting to Canadian dollars from Chinese Yuan. 


\section{Data Collection}

Once all interviews were completed and digital recorded, the interviews were transcribed verbatim. "Verbatim transcription of recorded interviews provided the best database for analysis" (Merriam, 2009). Field notes and personal notes of the non-verbal reactions of the participants augmented the database to support the verbal data provided. The transcripts were then coded for

themes based on the conceptual framework such as: Experience of Marginalization, Exploitation, and Oppression; Experience and Impact of Living in the new country, Policies and Support Programs for elderly immigrant women, and Suggestions for Change within Social Services for elderly immigrant women.

\section{Data Analysis}

After the data was transcribed, the researcher read and re-read the transcripts thoroughly for identifiable themes. In this process, the researcher searched for commonalities, some of which were outlined within the interview guide. However, the researcher also considered discrepancies among participant responses and searched for emerging themes that were not predetermined by the interview guide. Once the themes had been identified from the data, the researcher determined which were the most significant of the findings that effectively answered research questions. All data was analyzed in socialist feminist and anti-oppression perspective framework. Therefore, the exploitation of the women's "due role" was explored and the impact of oppression and marginalization were considered in analyzing the expressed lived experience of these women. In addition, how participants developed strategies to overcome the oppression environments in which they were immersed. Focusing on discrepancies among responses towards such things as causes of their poverty and lived experience was analyzed to represent the diversity of women who were in poverty. A phenomenological approach was utilized in order to assess the meaning 
that these women attached to their experience. Finally, post-modernism as an approach allowed the data of all the various lived experience of these women to be viewed as multiple realities and truths.

\section{Ethical Considerations}

All participants were informed on the participatory nature of the study. Each participant was instructed to have the right to withdraw their participation at any point. They were also informed that if any question asked they found difficult to answer, they had the permission to pass and not respond. In considering that the researcher would be asking participants to tell their stories, the researcher was aware that there would be a potential psychological risk in discussing emotionally difficult experiences. Prior to beginning each interview, all women were informed that they could determine what they wanted to and did not want to share. They were also informed that if any question made them uncomfortable she should feel open to reject to respond. In order to mitigate risks, all participants would have opportunity to receive a list of free or minimal cost on social-emotional support and one on one individual counselling service in Chinese. These services could be accessed easily at community agencies should they feel the need to seek support in this nature following the interviews.

\section{CHAPTER V: FINDINGS}

The changes of socio-economic status have a strong influence on the lives of elderly Chinese immigrant women observed in this study. Throughout the interviews with the four participants, a number of compelling themes emerged. Some of these themes were driven by the Narrative Interview Guide, such as Becoming Poor, Foreign Education Not Being Accepted, Problem with Employment, Doing House Work and Playing Caregiver Role, Elderly Chinese Immigrant Women's Mental Health. However, additional themes arose as a result of the women's narratives. 
For example, while the interview guide asked the women to talk about their experience becoming poor, some of the women also spoke that their lifestyle had changed and they were unable to access the Canadian pension programs. Finally, all women spoke how they develop strategies by talking with family members and trusted friends and supporting each other that allow them to be hopeful for the future.

\section{Becoming Poor}

Of the four women that were interviewed, all shared their different experiences with becoming poor. Commonalities among participant responses appeared that the four women all had experience living under the poverty level and the changes of their lifestyle. For these women, it is a major adjustment to a very different lifestyle in the new country. Although some women talk about finding ways to adjust to the changes their lives, regardless of the length of stay in Canada, none of them indicated that they liked to live in poverty. Women who were interviewed were asked to reflect on the experience of becoming poor. Wong describes her experience:

"I never know my life will be like this. I am getting poor as I do not have other financial resources".

"I have 2000 RMB pension from China. It is ok if I live in China but not in Canada. It is only about $\$ 300$ after being converted” (Han).

Two of the women interviewed indicated experiencing economic conditions that declined after moving to Canada. When asked how this change impacts their lives in Canada; these were their responses:

"My lifestyle has been changed significantly. I no longer meet friends outside (at restaurants) like what I did in China rather I am more likely to invite them to come over to my place"(Wang). 
"I do not spend much money on food and clothes. Most of my clothes were bought in China and brought to Canada" (Han).

For these individuals, the experience of becoming poor was evident and a consistent experience. All participants identified that when they came to Canada, they did not expect their economic status to decline and their lifestyle to change. These women expressed that the change of their lifestyle largely attributes to insufficient income they encountered. Two women spoke their experience of not being able to access the Canadian pension programs which also contributes to their poverty.

"I am getting poor as I am unable to access the universal Canadian pension even though I have passed 65 year old and have been living in Canada for 9 years" (Wang).

"Canadian pension is a universal program; every senior should have right to access it regardless they are immigrants or native - born" (Han).

It is apparent that these participants particularly feel they are excluded and discriminated by the Canadian pension system. However, what is obvious is that the exclusion and discrimination makes these women feel they are powerless.

These women already encounter the changes of their economic status and live under the poverty level, but it would appear they are more impacted by the lack of power to determine their economic condition. Li confirm this by stating:

"It is like you do not feel in control over your own life, particularly your financial situation after 
migration" (Chen).

This continues to represent a lack of power for the women in poverty. Giving them a financial situation in which they feel being excluded and stripped of rights to access the universal pension. Not only do these women identify feeling like they are discriminated against, but their experience of oppression has led to them feeling that they are being treated as others.

\section{Foreign education not being accepted}

There was a common theme for participants about their education credentials not being accepted by many employers. For these women, the experience of not being accepted and their credentials not being judged as equal to Canadian ones are apparent. Women who were interviewed were asked to reflect on this experience. Wong describes her experience by stating:

"I was asked if I have a Canadian degree or diploma when I apply for a job related to my field" (Li)

Two out of four participants expressed that they felt their credentials not being judged as equal as Canadian ones:

\footnotetext{
"No one was really interested in my Chinese education background; they (employers) all prefer Canadian credentials" (Li).

"I feel let down by the system here. I am a nurse and have over 20 years nursing experience in China, but I can do nothing here just because my diploma is from China rather than Canada" (Han).
}

One woman interviewed indicated her experience of being constantly rejected due to her credentials. She shared her experiences: 
"I applied many jobs upon arrival in Canada, but either no reply or being rejected due to without Canadian degree" (Chen).

It is apparent that these women feel the rejection is not simply interpreted as a rejection to their credentials, it implies that Canadian education is viewed as a standard and superior to nonCanadian education. Participants spoke that without a Canadian degree or diploma, they have less chance getting interviewed or being hired. All women feel they are discriminated against by many employers due to the credentials they have. However, what is obvious is that this discrimination makes participants feel their credentials are devalued. Li remarked:

"It seems Canadian credential is superior. It is totally unfair."

"I feel disappointed. I do feel my credential being devalued. Well, this is not only a credential, it seems I am judged not qualified" (Wong).

For these individuals, the experience of their credentials being devalued is not a single experience rather this experience occurred repeatedly. Two participants identified that they feel being discriminated against and this feeling become much stronger whenever they were rejected.

"I think it is not my credential. In fact, it is because I am a woman, a Chinese woman" (Li)

"If I am a white Canadian, the situation would be different" (Chen). 
It is apparent that participants feel the notion of foreign credentials not being accepted reflects on discrimination toward immigrant women. This example also reflects how dominant groups use power to devalue, discriminate, and exclude people with non-Canadian education.

Unlike these two women, Han at the time of interview had different perspectives on the rejection of her credential. She spoke that the experience of being frequently rejected made her feel that she was incompetent. It also made her lose self-confidence as she internalized that she is not capable. When asked to reflect her experience, Han stated as following:

"I feel that I am incapable or not good enough in comparing with other applicants after being rejected for several times. I do not have a Canadian credential. I have never felt so incompetent".

Clearly, this woman starts blaming herself and felt that it is her fault for not being accepted. The experience that this woman particularly identified that she not only experiences of the discrimination but also suffers internalized oppression.

One woman spoke that the unequal treatment toward the non-Canadian credentials had greatly impacted her integration into Canadian labour market and changed her economic status.

"Without a Canadian credential, I do not think I can find a similar job I had before. This definitely impacts my employment and economic status" (Li).

Participants also spoke of their experience being treated as older Chinese immigrant women with less education and lower professional status. One woman spoke about experiencing oppression through stereotype associated with being elderly Chinese immigrant women and discrimination. Some women even discussed how this experience results in feeling lower levels of self-esteem and self-efficacy. 
The literature reviews have explored older Chinese immigrant women has been perceived as having less education and lower professional status. In contrast to this, participants in this study all have relative higher education and professional careers prior to migration to Canada. The issue on foreign education credentials not being recognized reflects a power concept that forces people to consider the social inequality that impact participants' lived experience in the new country.

\section{Problem with employment}

The issue of unemployment become a common theme among participants. Many women spoke about the challenge associated with finding employment. Of the four participants, two women spoke that they tried so hard but could not find a same level of job they had before as their previous work experience and education not being recognized. For these women, the experience of not being able to get a job was evident. Women who were interviewed were asked to reflect on this experience. Li described her experience by stating:

"I tried so hard in finding a job related to my field. Many times I was very disappointed as they (employers) do not recognize my work experience in China” (Li).

"I have struggled in the labour market since I moved to Canada. It seems impossible to find a similar job I had before without Canadian education and work experience" (Wang).

These women encountered extremely difficulty in getting an employment in their professional field. Participants identified that they were discriminated against due to their previous education and work experience not being recognized. What is obvious is that the discrimination reflects power imbalance between dominant groups and subordinate groups. 
Two out of four participants at the time of interview spoke that they experience permanent unemployment; none of these women are able to find a job that matches their professional background. All participants expressed that they have experienced more or less being excluded and discriminated against when looking for a job. Three women who were interviewed were asked to reflect on their experience of being discriminated and excluded. These are their responses:

"I am in the situation with unemployment for a long time" (Han).

"Once a young man who is white with a Canadian education background and I both were interviewed, the Company finally hired him not me" (Li).

"I found that I had no chance at all, not even an interview. Who wants to hire an older immigrant woman?"(Wang).

It is apparent that despite the exclusion and discrimination of these women's education and work experience, participants also encounter discrimination due to their social identities of women, immigrants, old, and people of colour. Two participants expressed that without work, they experience of being marginalized in society. Given their employment situation, it is clear that the oppression based on gender, age, race, and immigrant status these women encounter is real. Two participants spoke that they had final given up looking for a job in their fields as they felt they would never have any chance to get it rather in order to survive, they work for unskilled, low-paid survival jobs that have nothing related to their previous education and work experience. One woman spoke that she helped babysitting kids for her daughter's friend. She describes her experience by stating:

“After numerous applications, I have given up to look for a professional job. I found a part-time job with a minimum wage and without any benefits (Chen). 
"I wish that I can find a job in my nursing field. However, this seems unrealistic. I am a self-employee now. I help my daughter's friend take care of her kids so that I can get some money to compensate the family" (Han).

For these individuals, the experience of unemployment significantly influences their lives in the new country. Participants who were interviewed expressed that they experienced of becoming poor. The poverty they encounter is largely attributed to the unemployment which results in the decline of their socio-economic status, particularly, the deterioration of their economic conditions.

When asked how the experience of unemployment impacts their integration into the Canadian society, participants at times had varying perspectives. Some women expressed that they would like to contribute to society with their knowledge and did not want to be labelled as a "burden". Others felt that the government needs to do more work to eliminate discrimination toward immigrant women and provide equal opportunities and rights on accessing labour market. Aside from how participants felt, there was also some discussion about oppression and powerlessness they encountered. All four participants spoke that being seniors and immigrant women, they found that they were in a more disadvantage position in society. They stated that many employers have power over applicants. If an individual speaks English with an accent, does not have Canadian work experience or education, or is too "old", they are not the person that the employers are interest in. That means they do not have any chances in the labour market as the employers have power in decision who they want. Participants clearly feel that there is a huge power gaps between employers and older immigrant women. 


\section{Doing House Work and Playing a Caregiver Role}

At the time of interviews, a common theme was highlighted on doing house work and playing a caregiver role among participants. Of the four participants, in this study all express that they more or less are involved in doing house work and helping their adult children take care of their grandchildren since they came to Canada. Women who were interviewed were asked to reflect on their experience. These are their responses:

"I help my son take care of my 2-year old granddaughter" (Li).

"My grandson, aged 7, is an elementary school student. Every day in the morning, I walk my grandson to his school and pick up him in the afternoon" (Chen).

"I help my daughter take care of my two grandchildren, aged eight and three years old" (Han)

Within the interviews, participants expressed that they have the responsibility to take care of their grandchildren. Most of these women also helped do some house works when their children went to work or school. Li described her experience by stating:

"I help cook meals and clean the house when my son and his wife not at home"

"Every Friday morning, I help to take the garbage out" (Wang).

"Yard works become my work; I help rake leaves and do the gardening" (Han). 
For these individuals, the experience of helping their adult children either taking care of their grandchildren or doing the house work was evident. Many women spoke that their children, also new immigrants, are unable to afford the expensive cost of daycare. Han remarked:

“At beginning they (her son and daughter-in-law) want to send her (granddaughter) back to China because only my son had a job, my daughter-in-law was studying at a college...they could not afford the cost of daycare"

"My children run a small business, they work long hours and often come home very late. The cost of daycare is not cheap" (Chen).

In these examples, it is apparent that the contribution of these women's labour greatly helps their children in reducing the cost of daycare. However, while exploring this theme, none of these Chinese women spoke that they got paid for what they had done. In contrast, these women felt that they are often viewed as "burden" to family and society. The experience of these women's domestic work not being acknowledged and valued is evident. While exploring house work, two women spoke about their experience by stating:

"My work is never counted as a "real work". I do not get paid. However, house work never end" (Chen).

“House work is always viewed as a woman's work. Hard work and without reward”(Wong).

These women's responses to house work reflect social injustice based on gender toward women's domestic labour. It also reflects the exploitation toward women's domestic labour that 
many women encounter in society. Over time, participants learn how gender inequalities produce the oppression that they encounter in their daily lives.

\section{Elderly Chinese Immigrant Women's Mental Health}

There is a common theme for participants about their mental health. Of the four women that were interviewed, three participants disclosed that they have experienced symptoms of anxiety and depression such as "insomnia", "feeling frustration, guilty, helpless, and unhappy". For these individuals, the experience of depression was evident. Women who were interviewed were asked to reflect on their experience. These are their responses:

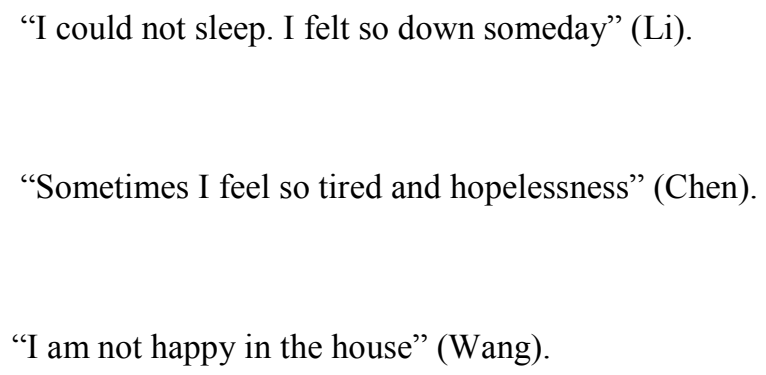

For these individuals, the experience of unhappiness, helplessness, and frustration was evident. While exploring the reason causing their depression, answers from participants are various. One woman spoke that her experience of unhappiness is due to being unable to work in her professional field. She described as following:

"I am not happy as my career has been ended. I am no longer able to work in the field I loved." (Li).

For this woman, the experience of unhappiness clearly relates to her unemployment after migration. However, what is obvious is that this unhappiness also relates to the experience of 
exclusion and discrimination toward immigrant women in the labour market as well as their feelings of powerless.

Unlike Li, Wong's experience of unhappiness is because she has insufficient pension. She shared her experience when she was asked:

"My daughter-in-law thinks I am poor because I do not have much pension. She does not want me to live with them. This makes me feel so upset" (Wong).

Another woman spoke about her experience of helplessness. She remarked: "Everything I have to rely on my daughter, everything. Like I have been living with my daughter since I moved to here even though I prefer to live alone... but I cannot afford an apartment on the expensive housing market. It is impossible. I feel so helpless" (Chen).

For these two women, the experience of upset and helplessness is closely associated with their insufficient income. However, it also reflects the oppression and powerless they encounter. It is apparent that the experience of depression for these women cannot be separated from their lower socio-economic conditions. The literature reviews have explored that women who worry about financial inadequacy are at greater risk of depression and have significantly poorer mental and affective well-being. They are also more likely to have lower life satisfaction. The literature reviews also show that recent immigrant women, especially those who migrated in their later age, have a higher risk of mental illness. In this study, participants identified that economic insecurity is one of key factors that results in their depression. All women expressed that depression also impacts their quality of life. In this sense, economic security is crucial to the mental health wellbeing of the participants. 


\section{Talking with Family members and Trusted Friends}

Talking with family members and trusted friends was a theme that emerged from this research when exploring how to develop strategies to overcome the oppressive environment and cope with the changes and challenges that these women encounter. Of four participants, three women spoke that they talk with family and trusted friends when they encounter changes and challenges in their lives. Women who were interviewed were asked to reflect on their experience. These women stated:

"I really need to talk with my friends about my lived experiences" (Wang).

"I like to talk with my sisters when I am in an oppressive environment" (Han).

"I would like to share my experience with my friends by talking with them. I found I was not alone" (Chen).

For these three individuals, the experience of talking with their families and trusted friends help them in dealing with discrimination, oppression, and marginalization they encounter based on their identities of women, immigrants, and elderly. One woman spoke about her experience by stating:

"Some people I talked with had experienced the similar situation so they understood what I say. This is really helpful" (Wang).

It is apparent that sharing experiences with their family numbers and trusted friends provides them with an opportunity to ventilate their feelings about lack of power, being discriminated, 
excluded, devalued and marginalized so that they obtain some emotional support and regain a sense of comfort and connection. Two participants spoke about their experience as following:

"Talking with family makes me feel comfortable and being understood. Sometimes I do not need them to say anything to me, I only want them to listen" (Han).

"Many elderly Chinese women are facing the same changes and challenges. I feel comfortable and being empowered after I talked with them" (Chen).

For these Chinese women, sharing their experience with their friends made them recognize that discrimination, oppression, and exclusion were not only related to themselves but also to other women as well. One woman explained:

"I really need to talk with my friends about my experiences after migration. I complain to them about my frustration and helplessness. I only want them to listen. I do not need them to say anything. I only wanted to ventilate my feelings. I felt comfortable after that" (Han).

Therefore, talking with family and trust friends is a practical strategy help participants to ventilate their feelings and regain power.

\section{Supporting Each Other}

Supporting each other as a theme emerged when participants expressed that they have interaction frequently with their friends who are also elderly Chinese immigrant women from China. Participants identified that they had a supportive relationship with those women when exploring "support". One participant expressed positive influence of having friends who had similar experiences. She spoke that she felt being understood when sharing her feelings and experiences with them. She said that she did seek support from her friends when encountering difficulties. However, three out of four participants identified that family was the first place where they went to get support. Wang remarked the following related to this theme: 
"My family always there for me, I have gotten great support from them, I always go to family first. Actually we support each other".

For this woman, the experience of getting support from her family is evident. Two women spoke that getting support from other people make them feel powerful. These are their responses:

"For me, getting support makes me feel that I am not alone. This is very powerful" (Chen).

"I believe that as immigrants, we can overcome the difficulties we encounter once we help and support each other. It is very important. ”(Li).

It is apparent that these women feel "support" is very important to them as getting support and support each other not only make them feel powerful but also help them overcome the oppression and discrimination they encounter in dealing with their lives in the new country. When exploring support from other elderly Chinese immigrant women in the community, responses from participants were mixed. One woman remarked:

"I would rather talk to my friends than other women. Some people may judge you" (Han).

Another woman's response was more positive, she spoke that talking with other Chinese women who came from the same cultural background provided her a chance to share her experience so that she could obtain emotional support and a sense of understanding. She also had opportunity to make more friends. She described her experience by stating:

\footnotetext{
"When facing the challenges and the stressors in the early time of migration, sharing experience with other Chinese women in the community became very important for me. It
} 
not only helped me ventilate my feelings of frustration, but also helped me make more friends who had experienced the same change." (Li).

For these individuals, supporting each other is a practical strategy that these women were empowered by sharing their experience with their families, friends, and other elderly Chinese women.

\section{CHAPTER VI: Discussion}

The change of socio-economic status, particularly the economic status, has a great impact on the lives of older Chinese immigrant women in Canada. In this study, the four participants were all well educated professionals prior to migration. With immigration to Canada, their socioeconomic status changed significantly. Many of them experience economic constraint and live under the poverty line.

Prior to conducting this research, I was aware that elderly Chinese immigrant women experienced oppression. However, this research provides me a great opportunity to understand how these women experience the oppression as well as the meaning that these women obtain from their experiences. The narratives of these women present reflect the causes of their oppressions and poverty were largely related to social structure inequality which is far beyond their personal control. It is clear that elderly Chinese immigrant women are constructed as "others". Many of their rights are taken away (credentials not being accepted, being excluded in the labour market, domestic work being devalued, and being not able to access the universal pension programs). They feel powerless due to their identity of being women, elderly, immigrants, and people of colour in society. All participants have experience of being discriminated against, exploited, marginalized and oppressed based on their gender, age, race, and class. Social workers in this field would benefit from adopting a socialist feminist and anti- 
oppression framework that would help them develop a better understanding women's oppression and encourage them to challenge the notion of power.

\section{Elderly Chinese Immigrant Women and Powerless}

Many of the responses these women had when exploring their lived experience (such as experiences of being devalued, discriminated, exploited, marginalized and excluded as well as lack of rights) clearly identify that they complete lack power. In nearly every interaction that they had within the public and the private spheres, these women were struggling to access any level of power. Within an anti-oppression and post-modernist perspective, power can be altered and is distributed along a hierarchy based on socially assigned identities where subordinate groups are often controlled by dominant groups. These relations of domination consist in the systematic devaluing and excluding of the attributes and contributions of those deemed inferior (Dominelli, 2002). In this sense, hierarchy results in one identity being regarded as superior to the other. It creates an "us-them" dynamic resulting in division and oppression. Based on this notion, elderly Chinese immigrant women are defined as an inferior group. Findings from this study affirm that Chinese women are often treated as "others" and controlled by the dominant groups. In this study, participants shared the experiences of their education credentials being devaluated and not accepted by many employers; some women being permanently unemployed; the others working in low-paid part-time jobs; and their house work being downplayed and not valued. Participants disclosed that they also experience being restricted to access the universal pension programs. All these examples reflect the power imbalance that dominant groups hold significant power over these Chinese women which make them have less power and feel powerless. 


\section{Foreign Education Credentials}

Foreign education credentials not being accepted as a theme was explored in this study. The impact of foreign education credentials not being accepted is significant. Participants spoke that they have experienced long-term unemployment as they could not find jobs in their professional field and their credentials are not being recognized and accepted by many employers. This reflects discrimination and racism toward foreign trained skill immigrants as their credentials are often devalued. In contrast, Western education is viewed as standard and superior to NonWestern education. Therefore, anyone who does not have the Western education background would be marginalized, excluded, and discriminated by the dominant white male control capitalist society, and thus, oppressed. This oppression is not only related to the systematic racism and discrimination toward immigrant women, it is also linked to the social structural inequality and power imbalance between the dominant groups and the oppressed groups.

\section{Elderly Chinese Immigrant Women and Poverty}

The interviews with participants identified that they were living in poverty regardless their education level or previous work experience. In this study, participants disclosed that they have post-secondary degree and professional work prior to migration. However, upon arriving to Canada, their socio-economic status changed dramatically. Particularly, their economic condition declined. Findings from this study support the general reviewed literature that elderly Chinese women are more likely to live under the poverty level and depend on their children socially and economically. This dependency mainly attributes to the fact that they are unable to participate in the Canadian labour market and their domestic labour is not valued. Moreover, these women are restricted to access the state pension programs. All these factors result in the seniors having less 
income, feeling economic insecurity, and living in poverty. Within the socialist feminist perspective, women's poverty attributes to labour division and gender inequality that women assume the "dual role"-domestic labour and wage labour as well as the discrimination of the state pension policy.

Compared to men and white women in the labour market, Chinese immigrant women struggle with occupational segregation, wage discrimination, part-time employment or unemployment. They have little job security due to the discrimination of their gender, race, class, and the state pension policies (Wang, 1997; Spence \& Koehn, 2010). Findings from this study affirm that most participants have hard times to find jobs in their professional field upon immigration to Canada. Half of participants are permanently unemployed. The other half of them have to work unskilled, low-paying part-time jobs so as to obtain more income and supplement their families. Findings in this study are consistent with previous studies that most of these women help their adult children take care of their grandchildren and do the household chores. Yet, they spoke that they never got paid. The experience of the dual role these women had is consistent with socialist feminist analysis that women's poverty is caused by gender inequality between men and women. However, it also related to class and race. For these Chinese women, the unemployment or the under-paid wage labour and the unpaid domestic labour cannot help them achieve economic selfsufficiency. As a result, the unjust interconnection between the two aspects of their lives makes them vulnerable to poverty and economic dependence.

Immigrant seniors' poverty and economic dependence is also attributed to state policies (Da \&Garcia, 2010). Kildal \& Kuhnle (2008) argue that historically the purpose of introducing universal old age pension is to alleviate poverty and income inequality in the old population so as to achieve fairness and respect to human dignity. Yet, the current Canadian pension policies not 
only do not address immigrant women's income inequality, but also contribute to their poverty. Because the Canadian pension policies discriminate and do not reach the immigrant seniors who migrate to Canada in their later-life. Findings from this study prove that the participants who are not able to meet the 10-year residence requirement by the Canadian pension policy are blocked to access the Canadian pension programs (Da \& Garcia, 2010; Spence \& Koehn, 2010). Overall, the social structure injustice in capitalist society based on gender, class, and race contribute to the elderly Chinese immigrant women's poverty.

\section{Elderly Chinese Immigrant Women and Mental health}

The responses from participants in this study identify that all these Chinese women have more or less symptoms of depression. It is clear that the depression they encounter is largely associated with the stressors from the deterioration of their socio-economic conditions. However, within a socialist feminism and anti-oppressive perspective, findings in this study affirm that these women's depression mainly attributes to the social structure injustice toward Chinese immigrant women in society as all these women have not only experienced being discriminated against in the labour market and but also have being exploited in the home. Apparently, these women do not have power in making decision about their lives in both public and private spheres. All these inequality and injustice that these women encounter in their daily lives make them feel depression. However, depression can seriously affect these women's mental health well-being.

\section{Limitations of Study}

The experience of elderly Chinese immigrant women in poverty has been examined. The focus is on recent arrived older immigrant women, who are well-educated from Mainland China, speak Mandarin, and are generally in good health. Their experiences of life and their strategies for dealing with the challenges in the new country may differ from those of Chinese women who are 
less educated, immigrate to Canada a long time ago, and experience physical illness. Thus, due to the low participant number, the results of this study cannot be generalized for all older Chinese immigrant women in Canada. Moreover, Noel (1996) stated that "immigrant women are not a homogenous group" (p.87). Feminist practitioners and researchers need to recognize women's unique ways of experiencing the world (Agnew, 1993). Therefore, data collected from the participants may not be equal. Some participants were very articulate, while others were somewhat guarded during the time of interview. The length of the interviewing time might be long for some seniors, they might feel tired. However, it might be short for the others because of the Narrative approaches were used. The interview questions were designed to be minimal and open end in order for these women to feel comfortable to express their lived experience. However, at times this resulted in shorter interviews where some participants were not able to share all their thoughts. This might make them feel uncomfortable.

In addition, since the researcher was a stranger to these women, they may have felt uncomfortable to disclose their lived experience in detail. Even with these limitations, the findings of this study added to the literature regarding older Chinese immigrant women in some meaningful ways. As a pilot study, the data provided a picture of lived experience of the older Chinese immigrant women due to the changes of their socio-economic statue.

\section{CHAPTER VII: Implication}

After carefully analyzing and reviewing the interviews of the four participants, a number of themes have emerged. First the impact of oppression on the lives of these four women is evident. It is reflected in how these women live in poverty and feel powerless. What is clear is that the lived experience of these women is discriminated, excluded, and marginalized due to their social identities of women, immigrants, elderly, and people of colour. They feel being treated as "others" 
as they experience unequal access to power. This unequal access to power results in these women having less access to resources on pension and opportunities in labour market. However, this is an issue related to social structural injustice toward elderly immigrant women. Therefore, a larger change is required so as to prevent further women from going through this experience. Since this situation not only impacts on elderly Chinese immigrant women, it may also affect older immigrant women from other ethnicities. I therefore would like to make the following recommendations to policy makers and social services providers so as to improve the lived experience for elderly immigrant women in Canada.

\section{Canadian Pension Policies}

The experience of oppression for elderly Chinese immigrant women has been displayed to be as a result of the discrimination, marginalization, and exclusion within society. The cause of these women's poverty can be various, however, there is no doubt that the Canadian pension policies have discriminated against immigrant seniors and contributed to their poverty because the policies do not properly deal with income inequalities and do not provide the poor a sufficient income. In contrast, the policies are designed to protect the interest of white men in society at the expense of women, immigrants and visible minorities. Based on the current pension policies, older immigrants have to reside in Canada ten years before becoming eligible for pension benefits. This policy has restricted immigrant seniors to access the Canadian pension programs. Furthermore, it has severely violated to the original intention of the development of the pension which is to combat poverty and income inequality in the old population (Kildal \& Kuhnle, 2008). Thus, the pension policies need to be re-evaluated and revised. The researcher recommends that the 10 years discriminated residence requirement should be eliminated so that elderly immigrant women have equal rights as Canadian born seniors to access the Canadian pension programs. In 
addition, their domestic work should be valued and paid by the government. The amount should be sufficient to allow them to live with independence and dignity (Da \& Garcia, 2010).

\section{Welfare Policy}

The current government immigrant policy has extended the sponsorship undertaking from 10 year to 20 year. This policy clearly increases dependency in the family. It reflects neo-liberal ideology that asserts values of self-reliance and "independence." However, in this context, "Independence" only means independence from state support. This policy denies women and elderly immigrants who have limited financial security and support to access the welfare state; it intensifies dependence on the family. This neo-liberal approach targets family reunion immigrants and implies that immigration of people in these categories has created a burden on Canadian society. This neo-liberal approach ignores the racism, classism, and sexism that block immigrants' successful integration into Canadian society and eliminates state responsibilities. It implies a "blame the victim" attitude. If an immigrant cannot integrate successfully, it is his or her shortcomings. This neo-liberal government view attempts to see social problems within an individual context. To this end, this approach only contributes to further poverty among elderly immigrant women as the judgements of who would become a "burden" and who would be "selfsupporting" are really based on gender, class, and race biased notions as to who have power or who do not have power to "contributes" to society and the economy. Therefore, the researcher suggests that greater understanding of the larger impacts and influences from larger structures is required. Also, there is a need for change to remove neo-liberal ideology when making policies by government policy makers. 


\section{Mental Health}

In discovering through literature reviews and research that elderly Chinese immigrant women from Mainland China have more serious depressive symptoms than Chinese men (Lai, 2004), Moreover, the prevalence of depression among older Chinese immigrant women is twice those of the general elderly population in Canada (Lai, 2004; Lai \& Chau, 2007; Spence \& Koehn, 2010). Many women in this study have experienced the feelings of frustration, helplessness, and powerlessness due to the pressure of finding a job, abrupt decline in financial income, and living in poverty. They expressed being discriminated against, excluded, exploited, and marginalized based on their education credentials, work experiences, gender, race, age, and immigrant status etc. Therefore, elderly immigrant women's mental health cannot be viewed as an individual issue. It is really related to a social structure injustice toward immigrant seniors. In working with elderly immigrant women, service providers need to acknowledge not only the changes of migration in their lives, but also to understand the impact of social injustice such as sexism, racism, classism and ageism result in their depression. Recognizing the power imbalance and the intersection of oppression immigrant senior women encounter is very important in providing services to women with mental illness. For instance, the conservative government cut social programs such as mental health and settlement which directly impact immigrant senior women's mental health well-being. Therefore, with this knowledge in mind, policy makers and service providers need to adopt AOP perspective and advocate for immigrant senior women while developing policies and providing service to the elderly Chinese women by referring them to appropriate programs and helping them alleviate stress so as to meet their needs.

\section{Address Issues of Discrimination and Marginalization}

Elderly Chinese immigrant women have been discriminated and marginalized in the patriarchy capitalist society. According to Mehr (2013), sexism, racism, classism, and ageism are often 
viewed as an individual problem rather than an institutional problem. Therefore, the researcher suggests that it is the duty of social service providers to understand ethnic minority client's experience and effectively address their needs and the problems of discrimination and marginalization. Elderly Chinese immigrant women can be empowered by carefully listening to their stories and helping them understand social structure inequality based on gender, class, race, and age both in the labour market and at home when working with the oppressions they encounter. In addition, government programs and policies should be tailored to elderly immigrant women, taking into account their special needs. Particularly, programs that deal with financial barriers and all forms of discrimination and marginalisation should be of high priority for the policy makers and social service providers concerned with the well-being of elderly immigrant women.

\section{Social Support: Senior Housing, Public Transportation, and Childcare Services}

In discovering through literature reviews and research that many elderly Chinese immigrant women have experience living with adult children, providing children care, and lack of social activity due to expensive transportation fares. Unlike the native-born seniors, these women who are age of 65 and over are more vulnerable in terms of income because they are more likely to not have enough time to accumulate wealth through labour market participation and to have home ownership and savings (Angel et al., 1999; the National Seniors Council on Low Income Among Seniors, 2011). Thus, social supports greatly influence the life of elderly immigrant women and play an important role in the health of immigrant seniors (Hurdle, 2001). In working with elderly immigrant women, service providers need to acknowledge their needs and recognize the oppression they encounter in their daily lives. Moreover, service providers need to be aware the power imbalance between the service providers and the service users. With this knowledge in 
mind, I recommend that policy makers and service providers need to adopt AOP perspective in terms of dealing issues related to senior housing, public transportation, and childcare services and advocate for immigrant senior women while developing policies and providing services. From this point, the researcher recommends that senior housing and free public transportation should be available to immigrant seniors. Moreover, childcare services should be affordable and accessible to all Canadian families so that they do not have to depend on their elderly parents to take care of their children (Da \& Garcia, 2010). Also, childcare services should be sensitive to cultural difference and tailored to meet the needs of children and families who speak a language other than English/French at home.

\section{CHAPTER VIII: CONCLUSION}

This study has explored the lived experiences of four elderly Chinese immigrant women in Toronto. Oppression in the lives of these women has been identified. It is clear that elderly Chinese immigrant women in poverty are not an individual issue. This study examines how the social structure injustice based on gender, class, race, immigrant status, and age results in the elderly in poverty. In a post-modern paradigm the narratives of these women have been examined as multiple realities. One of the most common themes in the findings of this research is that these Chinese women experienced a lack of power and were oppressed in both public sphere - the labour market and private sphere - the home.

This study focuses on the causes of these Chinese women's poverty. With the socialist feminism and anti-oppressive perspective, this research attempts to analyze how the "dual role" these women combine in their lives and how the state pension policies contribute to their poverty. Through narratives of the lived experience of being an elderly Chinese immigrant women and exploring the meaning that the women attach to this experience, the experiences of 
discrimination, exclusion, devaluation, and marginalization these women have encountered are highlighted. This study also provides insight to the women's strategies to regain a sense of selfconfidence in the situation which initially made them feel helpless, powerless, and devalued. There is no doubt that sharing their personal experiences and strategies can increase their awareness of the existence of sexism, racism, and ageism in the dominant society and empower them to dealing with the issues related to social injustice.

In order to change the oppressive structures that maintain marginalization of women in society, approaches need to be taken that work to deconstruct how society views the issues of elderly immigrant women in poverty. This approach requests workers to see elderly immigrant women as unique individuals and understand their needs, feelings, oppressions, changes and the power relations between these women and the environment around them.

It also requests workers to establish equal partnerships with these women and find out the underlie issues related to their poverty. Together with them to discuss their concerns and to analyse the relations of powers, use deconstruction, anti-oppression and empowerment framework to challenge the existence of social injustice. This requests service providers to value these women's experiences and to see that they are the "experts" on what their needs are. In the meantime, workers would benefit from utilizing critical theory to assess power dynamics that affect these women. Critical theory challenges service providers to question notion of power and to understand diverse cultural origins of knowledge, and critically explore relationships between clients and workers.

Additional research is requested to examine the impact of oppression on the lived experience of these women as well as the social support for the seniors. Without this change in discourse, elderly Chinese immigrant women will still live in poverty. 


\section{Reference:}

Agnew, V. (1993). Canadian feminists and women of colour. Women's Studied International Forum. 16(3), 217-227.

Angel, J. L., \& Angel. R. J. (1992). Age at migration, social connections, and well-being among elderly Hispanics. Journal of Aging and Health, 4, 480-499.

Angel, R., Angel, J. L., Geum-Yong, L., Markides, K. S. (1999). Age at migration and family dependency among older Mexican immigrants: Recent evidence from the Mexican American EPESE. The Gerontologist. 39(1), 59-65.

Angel, R., \& Tienda, M. (1982). Determinants of extended household structure: Cultural pattern or economic need? American Journal of Sociology, 87(6), 1360-1383.

Auger, J.A. \& Tedford-Litle, D. (2002). From the inside looking out: competing ideas about growing old. Halifax: Fernwood

Avendano, M., Boshuizen, H. C., Schellevis, F.G., Mackenbach, J. P., et al. (2006). Disparityes in stroke preventive care in general practice did not explain socioeconomic disparities in stroke. Journal of Clinical Epidemiology, 59 (12), 1285-1294.

Bassuk, S. S., Berkman, L. F., Amick, B.C. (2002). Socioeconomic Status and Mortality among Elderly: Findings from Four Communities in the United States. Am. J. Epidemiol. $15 ; 155(6), 520-33$.

Bogdan, R., \& Biklen, S. K. (2007). Qualitative research for education: an introduction to theory and methods: Pearson/Allyn and Bacon.

Bowling, A. (2005). Growing older: Ageing well, quality of life in old age. England: Berkshire Open University Press 
Boyd, M. (1991). Immigration and living arrangements: Elderly women in Canada. International Migration Review, 25(1), 4-27.

Buchmann, \& Hannum. (2001). "Education and stratification in developing countries: A review of theories and empirical research." Annual Review of Sociology. 27, 77-102.

Boyd, M., \& Kaida, L. (2011). Poverty variations among the elderly: The Roles of Income Security Policies and Family Co-Residence. Canadian Journal on Aging, 30(1), 83-100.

Camey, P. (1992). The concept of poverty. Public Health Nursing. 9, 74-80.

Carniol, B. (2005) 'Analysis of social location and change: Practice implications' in S. Hicks, J. Fook and R. Pozzuto (eds) Social Work: A Critical Turn. Toronto: Thompson Educational Publishing.

Canadian community health survey (2003). Retrieved 28 August, 2013, from

http://www23.statcan.gc.ca/imdb/p2SV.pl?Function=getDatafileData\&Item_Id=46547\&lang=en $\& \mathrm{db}=\mathrm{imdb} \& \mathrm{adm}=8 \& \mathrm{dis}=2$

Canadian community health survey (2012). Retrieved 30 August, 2013, from http://www.statcan.gc.ca/daily-quotidien/130617/dq130617b-eng.pdf

Carter, S. \& Little, M. Justifying knowledge, justifying method, taking action: Epistemologies, methodologies, and methods of qualitative research. Qualitative Health Research, 17 (10), $1316-1328$.

Chappell, N. L., \& Badger, M. (1989). Social isolation and wellbeing. Journal of Gerontology, 44(5), 169-176.

Chard, J. (2000). "Women in a Visible Minority". In C. Lindsay, ed. Women in Canada 2000: A Gender-Based Statistical Report. Cat. No. 89-503-XPE. Ottawa: Statistics Canada.

Chesley, N. \& Poppie, K. (2009). Assisting Parents and In-laws: Gender, Type of Assistance, 
and Couples' Employment. Journal of Marriage and Family, 71, 247-262.

Chow, H. P.H. (2010). Growing old in Canada: physical and psychological well-being among elderly Chinese immigrants. Ethnicity \& Health.15 (1), February 2010

Combs, G. \& Freedman, J. (2012). Narrative, Poststructuralism, and Social Justice: Current

Practices in Narrative Therapy. The Counselling Psychologist 40(7) 1033-1060

Cutler, D. M., Knaul, F., Lozano, R., Mendez, O., \& Zurita, B. (2002). Financial crisis, health outcomes and ageing: Mexico in the 1980s and 1990s. Journal of Public Economics, 84(2), 279-303.

Cresswell, J.W. (2007). Qualitative inquiry and research design: Choosing among five approaches. (2th ed.). Thousand Oaks, CA:Sage

Da, W. \& Garcia, A.(2010). An Exploration of Socio-cultural Adaptation and Changes in Quality of Life at Settlement among Older Chinese Immigrants in Canada. CERIS Working Paper No.80

Dean, A., Kolody, B., Wood, P. Matt, G. (1992). The influence of living alone on depression in elderly persons. Journal of Aging and Health, 4 (1), 3-18

Dempsey, C. (2005). Elderly immigrants in Canada: Income sources and self-sufficiency. Ottawa, Ontario, Canada: Citizenship and Immigration Canada. Retrieved August 15, 2013, from http://www.cic.gc.ca/english/pdf/research-stats/elderly.pdf

Diener, E. \& Biswas-Myers, R. (2002) Will money increase subjective well-being? Social Indicators Research, Volume 57, 119-69.

Dominelli, L. (2002). Anti-oppressive social work theory and practice. New York: Palgrave Macmillan. 
Eaton, W. W., Muntaner, C., Bovasso, G., \& Smith, C. (2001). Socioeconomic status and depressive syndrome: The role of inter and intragenerational mobility, government assistance, and work environment. Journal of Health and Social Behavior, Volume 42. 277-294.

Fenge, L., Hean, S., Worswick, L. Wilkinson, C., Fearnley \& Ersser, S. (2012). The impact of the economic recession on well-being and quality of life of older people. Health and Social Care in the Community. 20(6), 617-624

Fitzgerald, T. (2004). Powerful voices and powerful stories: reflections on the challenges and dynamics of intercultural research. Journal of Intercultural Studies, 25 (3), 233-244.

Gazso, A. (2005). The poverty of unattached senior women and the Canadian retirement income system: A matter of blame or contradiction? Journal of Sociology and Social Welfare, 32(2), 41-62.

Gee, E. M. (1999). Living arrangements and quality of life among Chinese Canadian elders. Social Indicators Research, 51 (3), 309-329.

Gelderloos, P. (2005). “The Rise of Hierarchy” Retrieved July 25, 2013, from http://curiouspraxis.wordpress.com/prefigurative_politics_anthropological_practic/1hierarchy-oppression-methodologies/1-2-hierarchy-oppression-a-framework-for-antioppressive-analysis-practice/

Ginsberg, Y. (2006). Separate or together - Housing policies regarding elderly immigrants from the Former Soviet Union. International Sociological Association, Durban South Africa. Guido, F. M., Chávez, A. F., \& Lincoln, Y. S. (2010). Underlying paradigms in student affairs research and practice. Journal of Student Affairs Research and Practice, 47(1), 1-22.

Guo, S. \& Devoretz, D.J. (2006). The changing face of Chinese immigrants in Canada. Journal of International of Migration and Integration, 7 (3), 275-300. 
Hamilton, R. (1996). Gendering the vertical mosaic: Feminist perspectives on Canadian society. Toronto: Copp Clark.

Harvey, D. (1990). The condition of postmodernity: An enquiry into the original of cultural change. Black well, Cambridge MA \& Oxford UK.

Healy, K. (2005). Social work theories in context: Creating frameworks for practice. Palgrave Macmillan.

Hemingway, H. \& Marmot, M. (1999). Evidence based cardiology: Psychosocial factors in the aetiology and prognosis of coronary heart disease: systematic review of prospective cohort studies. Clinical review, BMJ Volume 318, 1460-1467.

Heron, B. (2005). Self-reflection in critical social work practice: subjectivity and the possibilities of resistance. Reflective Practice, 6 (3), 341-351.

Heylighten, F. \& Bernheim, J. (2000) Global progress I: empirical evidence for ongoing increase in quality of life, Journal of Happiness Studies, I: 323-49.

Huguet, N., Kaplan, M. S., \& Feeny, D. (2008). Socioeconomic status and health-related quality of life among elderly people: Results from the Joint Canada/United States Survey of Healthstar. Social Science \& Medicine. 66, 803-810.

Hunter, M. (2002). Rethinking epistemology, methodology, and racism: or, is white sociology really dead? Race \& Society, Volume 5, 119-138.

Hurdle E. Donna (2001). Social support: A critical factor in women's health and health promotion. National Association of Social Workers.

Kaida, L. \& Boyd, M. (2011). Poverty variations among the elderly: the roles of income security Policies and family co-residence. Canadian Journal on Aging, 30 (1), 83-100. 
Kildal, N. \& Kuhnle, S. (2008). Old Age Pensions, Poverty and Dignity: Historical Arguments for Universal Pensions. Global Social Policy. SAGE Publications

Kim,S. (2002). The effects of socioeconomic status, social support, and acculturation on the mental and physical health among Korean American older adults in Chicago metropolitan area. A Dissertation Submitted to the Graduate Faculty of the Louisiana State University and Agricultural and Mechanical College

Lai, D.W.L. (1995). Life satisfaction of Chinese elderly immigrants in Calgary. Canadian Journal of Aging, Volume 14, 536 - 552.

Lai, D. W.-L.(2000). Prevalence of depression among the elderly Chinese in Canada. Revue Canadienne De santé Publique. 91(1)

Lai, D.W.L.(2004). Depression among elderly Chinese-Canadian immigrants from Mainland China. Chinese Medical Journal, 117(5), 677-683.

Lai, D.W.L. and Chau, S.B.Y., 2007. Predictors of health service barriers for older Chinese immigrants in Canada. Health and Social Work, 32 (1), 57- 65.

Lai, D.W.L. \& Leonenko, W.L. (2007). Correlates of living alone among single elderly Chinese immigrants in Canada. International Journal of Aging and Human Development, 65(2): 121148.

Lai, D.W.L. (2010). Filial piety, caregiving appraisal and caregiving burden. Research on Aging, 32 (2), 200-223.

Lai, D.W.L. (2011). Perceived Impact of Economic Downturn on Worry Experienced by Elderly Chinese Immigrants in Canada. Journal of Family and Economic, 32 (3), 521-531.

Lewin, S. (2003). Immigration, State Support, and the Economic Well-Being of the Elderly in Israel. Research On Aging, 25 (3), 195-223. 
Li, P.S.(2010). Immigrants from China to Canada: Issues of Supply and Demand of Human Capital. Canadian International Council. www.canadianinternationalcouncil.org Li, Y. (2008). An empirical study of recent mainland Chinese migration to Vancouver. Journal of the Canadian Historical Association. 19 (2). 180-196.

Mehr, F.S. (2013). Addressing Factors Related to Depression \& Mental Health in Elderly Chinese Immigrant Women in Ontario, Thesis, Department of Sociology and Anthropology Faculty of Social Sciences University of Ottawa

Merriam, S. B. (2009). Qualitative research: A guide to design and implementation: Jossey-Bass Inc Pub.

Moustakas, C. (1994). Phenomenological research methods. Thousand Oaka, CA: Sage.

Moritz, D. J., Kasl, S. V., \& Berkman, L. F. (1989). The health impact of living with a cognitively impaired elderly spouse: Depressive symptoms and social functioning. Journal of Gerontology: Social Sciences, 44 (1). S17-27.

Mullaly, B. (2007). "Working Outside (and Against) the System: Radical Structuralism and Working within Ourselves" in The New Structural Social Work, Oxfor University Press.

Naiman, J. (2008). How societies work: class, power, and change in a Canadian context. Canada, Halifax and Winnipeg, Fernwood publishing

National Advisory Council on Aging. (2005). Retrieved 26 August, 2013, from http://publications.gc.ca/collections/Collection/H88-5-3-2005E.pdf National Seniors Council on Low Income Among Seniors (2011). Retrieved 24 August, 2013, from http://www.seniorscouncil.gc.ca/eng/research_publications/low_income/2009/hs1_9/page00.sht $\mathrm{ml}$ 
Newman, S. C., Bland, R. C., \& Orn, H. T. (1998). The prevalence of mental disorders in the elderly in Edmonton: A community survey using GMS-AGECAT. Canadian Journal of Psychiatry. www.cap-apc.org

Novak, M. and Campbell, L. (2006). Aging and society: A Canadian perspective, 4-15. Toronto, Canada: Thomson \& Nelson.

Olesen,V. (2005). Early millennial feminist qualitative research: Challenges and contours. The Sage handbook of qualitative research. $3^{\text {rd }}$ ed., pp. 235-278. Thousand Oaks, CA: Sage.

Palameta, B. (2004). Low Income among Immigrants and Visible Minorities. Perspective_on Labour and Income, 16 (2), 32-37.

Pedersen, S., Denollet, J., Spindler, H., Ong, A., Serruys, P., Erdman, R., et al. (2006). Anxiety enhances the detrimental effect of depressive symptoms on health status following percutaneous coronary intervention. Journal of Psychosomatic Research, 61(6), 783-789.

Perl, E. J., \& Noldon, D. F. (2000). Overview of Student Affairs Research Methods: Qualitative and Quantitative. New Directions for Institutional Research, 2000(108), 37-48.

Pérez, C. 2002. "Health Status and Health Behaviour Among Immigrants" Supplement to Health Reports. Vol. 13. Statistics Canada Catalogue no. 82-003. Ottawa.

Picot, G., Lu, Y., \& Hou, F. (2009). Immigrant low-income rates: The role of market income and government transfers. Perspectives on Labour and Income, 10 (12), 13-27.

Picot, G. \& A. Sweetman. (2005). “The Deteriorating Economic Welfare of Immigrants and Possible Causes: Update 2005” Research Paper-Analytical Studies Branch Research Paper Series. Statistics Canada Catalogue no. 11F0019MIE. Ottawa. No. 262.

Pilowsky, J. E. (1991). A population at risk. Healthsharing. 21-24. 
Pilowsky, J. E. \& Mor, S. (1990). Support systems available to abused immigrant women in metropolitan Toronto. Ontario Women's Directorate.

Pinquart, M. \& Sorensen, S. (2000). Influence of socioeconomic status, social network, and competence on subjective well-being in later life: A meta-analysis. Psychology and Aging, 15 (2), 187-224.

Portes, A., \& Rumbaut, R.G. (1990). Immigrant America: A Portrait. Publisher: University of California Press.

Reinhan, S. ( 1992). Feminist method in social research. New York: Oxford University.

Rendall, M.S., \& Speare, A. (1995). Elderly poverty alleviation through living with family. Journal of Population Economics, 8(4), 383-405.

Revicki, D. A., \& Mitchell, J. P. (1990). Strain, social support, and mental health in rural elderly individuals. Journal of Gerontology: Social Sciences, 45 (6). S267-274.

Sanghera, G.S. (2010). Diversity and aging among immigrant seniors in Canada: Changing faces and greying temples. Detselig Enterprises Ltd. Calgary, Alberta

Service Canada. (2012). Overview of the old age security program. Ottawa, Ontario, Canada: Service Canada. Retrieved November 30, 2012, from

http://www.servicecanada.gc.ca/eng/isp/oas/oasoverview.shtml

Shields, J., Kelly, P., Park, S., Prier, N., \& Fang, T. (2011). Profiling immigrant poverty in Canada: A 2006 census statistical portrait. Canadian Review of Social Policy.

Smith, S.L. (2013). African American females in senior-level executive roles navigating predominately white institutions: experiences, challenges and strategies for success. A dissertation for the Faculty of the Graduate School of The University of Texas at Austin Spence, M \& Koehn,S. (2010). ICARE: Immigrant Older Women - Care Accessibility Research 
Empowerment. "Immigrants and Refugees" issue of Visions Journal, 6 (3), p. 17 http://www.heretohelp.bc.ca/visions/older-adult-immigrants-and-refugees-vol6/icare-immigrantolder-women-care-accessibility-research-empowerment Statistics Canada. (2006). A portrait of seniors in Canada. Retrieved 30 August, 2013, from http://www.statcan.gc.ca/pub/89-519-x/89-519-x2006001-eng.pdf

Tran, T.V., G. Khatutsky, K. Aroian, A. Balsam, and K. Conway. (2000). Living arrangements, depression, and health status among elderly Russian-speaking immigrants. Journal of Gerontological Social Work, 33(2): 63-77.

Turcotte, M., \& Schellenberg, G. (2007). A portrait of seniors in Canada: Ottawa, Ontario, Canada: Statistics Canada (Catalogue no. 89-519-XIE). Retrieved August 24, 2009, [End Page 99] from http://www.statcan.ca/english/freepub/89-519-XIE/89-519-XIE2006001.pdf Uhlenberg, P., \& Miner, S. (1996). Life course and aging: A cohort perspective. In R. H. Veenhoven, R. (1991) Is happiness relative? Social Indicators Research, Volume 24, 1-34 Walby, Sylvia, 1990. Theorizing Patriarchy, Oxford: Basil Blackwell Ltd.

Wang, S. H. (1997). The experiences of Chinese immigrant women with the health care delivery system in Canada. A dissertation submitted to the Graduate Faculty of Nursing of Dalhousie University, Halifax, Nova Scotia.

Wang, S. and Lo, L. (2004). Chinese immigrants in Canada: Their changing composition and economic performance. Working Paper Series No. 30. Toronto: The Ontario Metropolis Center. Page 21

Watari, K. F., \& Brodbeck, C. (2004). Culture, health, and financial appraisals: Comparison of worry in older Japanese Americans and European Americans. Journal of Clinical Geropsychology, 6(1), 25-39. 
Wilkinson, A., Dundon, T., Marchington, M., \& Ackers. P. (2004). Changing patterns of employee voice: case studies from the UK and Republic of Ireland. Journal of Industrial Relations, 46 (3), 298-322.

Yee. M. (1987). Chinese Canadian women: Our common struggle. Canadian Ethnic Studies. 19(3), $174-185$.

Yeung, W. J., \& Hofferth, S. L. (1998). Family adaptations to income and job loss in the U.S. Journal of Family \& Economic Issues, 19(3), 255-283.

Yeung, W. J. \& Xu, Z. (2011). Economic Stress, Quality of Life, and Mortality for the OldestOld in China. Social Indicators Research, 108 (1), 131-152.

Young, I. M. (1990). Five faces of oppression, Justice and the politics of difference, Princeton University Press, pp. 39-65. 


\section{Appendix A: Recruitment Text}

\section{Understanding the Experience of Older Chinese Women Whose Socio-economic Status Changed Dramatically after Immigrating to Canada}

\section{Seeking Participants for Study about Changes of Socio-Economic Status - Experience of Older Chinese Immigrant Women in Canada}

(To be translated into Chinese)

My name is Qi Mao. I am currently completing a Master of Social Work degree at Ryerson University. I am in the process of recruiting participants for a small study about the experience of older Chinese immigrant women whose socio-economic status changed after immigrating to Canada.

The focus of this study is to understand the nature of the relationship between socio-economic status and the lives of older Chinese immigrant women. Particularly whether change of socioeconomic status impacts their everyday lives in the host country. Since these is little research on the issue so far that has been conducted about the recent arrivals, I feel it is important to have this study because older Chinese immigrant women as an ethnic minority group in Canada have seldom been heard by the mainstream. I hope this work can provide an opportunity to share your experiences and challenges and give voices for you. I also hope this work can contribute to promote social justice not only for older Chinese women but also benefit older immigrant women from other racial minority groups. I particularly welcome the participation of those who identify themselves as Chinese, are from Mainland China, speak Mandarin, are between 60 and 
80 years old, have college or university education background, worked as a professional in China prior to retirement, and have resided in Canada for less than 10 years to participant this study. This process will involve a 1 to 1.5 hour audio recorded interview. The interview will not be conducted in public settings. In order to protect privacy and safety of both the participant and the researcher, a room or an office at public libraries, the community centre, or Ryerson University will be booked. Face-to-face interviews will be conducted between the researcher and the participants who are in Great Toronto Area. All information shared will be confidential and no names or identifying information will be published or shared in any way. Participation is entirely voluntary and you can choose to end your involvement with the study at any time.

My concern about this issue arises from my personal experience. I am an immigrant from Mainland China. I have aging parents who currently live in Bejing. I studied gerontology and have worked with seniors in community, long-term care and hospital settings in past years. All these personal experiences have strongly influenced my life, my family as well as my thinking toward the aging population.

For more information, please contact me at qi.mao@ryerson.ca or (416) 979-5000 ext 4789.

Thank you,

Qi Mao

MSW Candidate, 2013

Ryerson University 


\section{Appendix B - Interview Guide}

\section{Understanding the Experience of Older Chinese Immigrant Women Whose Socio- Economic Status Changed Dramatically after Immigrating to Canada}

(To be translated into Chinese)

Preamble: Thank you for agreeing to be part of this research process. Before we start, I would like you to know that this interview will take approximately 1 to 1.5 hours. I also want to assure you that in this study, everything you say here is confidential and that only I and my research supervisor will have access to the information you provide. All identifying information will be removed in the study and a pseudonym will be used if you are quoted. Before we begin, I would like to ask your permission to record the interview. At any point during the interview, you may ask to stop the recording or take a break. You can also terminate the interview at any time if you feel any discomfort or you change your mind about being part of this research study. Do you have any questions before we begin?

1. What is the highest level of education you have received?

2. What kind of occupation did you have prior to your retirement?

3. Whether your education has played an important role in your later life?

4. How do you see your socio-economic status after migration to Canada?

5. How do you see economic status and your leisure activities?

6. How do you see economic status and your health?

7. What does it mean to be an elderly Chinese immigrant woman in the host country? 
8. How do you see your relationship with your children or grandchildren?

9. What social policies may affect your lived experience?

10. How do you describe your life experiences in the new country?

11. What factors do you think may affect your quality of life?

12. Do you feel happiness and satisfaction for your life in Canada?

13. How do you cope with the challenges? 


\section{Appendix C - Consent form}

\section{RYERSON}

UNIVERSITY

\section{SCHOOL OF SOCIAL WORK}

\section{FACULTY OF COMMUNITY SERVICES}

Accredited by The Canadian Association for Social Work Education

\section{Understanding the Experience of Older Chinese Immigrant Women Whose Socio- Economic Status Changed Dramatically after Immigrating to Canada}

(To be translated into Chinese)

You are being invited to participate in a research study. Before you give your consent to participate, it is important that you read the following information and ask as many questions as necessary to be sure you understand what you will be asked to do.

\section{Investigator:}

Qi Mao- Master of Social Work Candidate, Expected 2014

\section{Supervisor:}

Lisa Barnoff, PhD - Director and Associate Professor, Ryerson School of Social Work

Purpose of the Study: Previous studies show that there is a large portion of higher poverty rates with elderly immigrants, particularly, minority older immigrant women are economic vulnerable. Literature indicates that many older immigrant women from China not only bear poverty but also have a higher rate of depression. However, these studies only discuss pieces of the issues on older immigrant women. It does not go further to exam the nature of the relationship between socio-economic status and their lives in old age. Especially, whether change of socio-economic status impacts their life in the host country because many research studies consistently suggest 
that socio-economic status may influence older immigrants in their later lives. This study focuses on understanding the experiences of older Chinese immigrant women whose socio-economic status changed dramatically after immigrating to Canada. The aim of the research is to promote social justice, to give a voice to older Chinese immigrant women, and to make recommendations for policymakers and social service providers.

Use of Data: The information which participants share in interviews will be used for two purposes. The first purpose is to accomplish a supervised Major Research Paper submitted to Ryerson University in partial completion of a Master of Social Work degree. As the scope of this paper is limited, only data from some participants will be included. The second purpose will be a subsequent unsupervised manuscript intended for publication in a peer-reviewed journal. Data from all participants will be included in this manuscript. Both manuscripts will have the same focus.

Description of the Study: Data will be collected during a one-on-one, face-to-face interview. The interview will be conducted in a booked room and/or office at public libraries, the community centre, or Ryerson University so as to provide safety and aural and visual privacy for both the participants and the researcher. If you agree to be a part of this study, you will be asked to participate in a audio recorded, approximately 1-1.5 hour interview, that will ask you about your experience as an immigrant in Canada. Topics explored will include how you view your life in Canada as an older immigrant / what you have experienced in terms of poverty and depression/ what factors may lead you to live in poverty and depression/ how depression and poverty might affect your quality of life. The audio recordings will be transcribed by the researcher personally.

\section{Please initial here to indicate that you have read this page:}


Risks or Discomforts: You might experience discomfort during the interview because of the length or because of the emotional nature of the discussion. In order to mitigate risks, you will have the opportunity to receive a list of free or minimal cost social-emotional support and one on one individual counselling service in Chinese. These services can be obtained at community agencies such as Carefirst Seniors, Family Service Toronto, WoodGreen Community Service, or COSTI. Please note that you can stop the interview, take a break, or withdraw at any time during the interview process or after it has taken place. If you decide to withdraw, all data collected from you will be destroyed and will not be included in the study.

Benefits of the Study: I hope that this study will give you the opportunity to share your stories, your needs, and your concerns as an older immigrant from China. I also hope that this research will bring out your voice and help policy makers and social service providers making policies and providing services to a diverse population. However, I cannot guarantee benefits from participating in this study.

Confidentiality: Only the student investigator and the supervisor will have access to the data collected. The data from interviews will be audio recorded and transcribed by the PI personally. All identifying information will be removed from transcripts and pseudonyms will be used to ensure confidentiality. Transcripts and electronic recordings will be password protected, stored at Ryerson University and deleted after five years.

Voluntary Nature of Participation: Participation in this study is voluntary. Your choice of whether or not to participate will not influence your future relations with Ryerson University. If you decide to participate, you are free to withdraw your consent and to stop your participation at 
any time before the final report has been written. At any point in the study, you may refuse to answer particular questions or stop participation.

Future Contact: If you consent to be contacted for the purpose of sharing the study findings, you will be contacted when the study is completed via email or phone, as your prefer.

Questions about the Study: If you have any questions about the research now, please ask. If you have questions later about the research, you may contact:

\section{PI/Study Coordinator:}

Qi Mao - (416) 979-5000 Ext 4789

qi.mao@ryerson.ca

\section{Study Supervisor:}

Lisa Barnoff- (416) 9795000 x 6243

lbarnoff@ryerson.ca

If you have questions regarding your rights as a human subject and participant in this study, you may contact the Ryerson University Research Ethics Board for information:

Toni Fletcher, Research Ethics Coordinator

Ryerson University

350 Victoria Street

Toronto, ON M5B 2K3

416-979-5042 / rebchair@ryerson.ca

Please initial here to indicate that you have read this page: 


\section{Agreement:}

(To be translated into Chinese)

Your signature below indicates that you have read the information in this agreement and have had a chance to ask any questions you have about the study. Your signature also indicates that you agree to be in the study and have been told that you can change your mind and withdraw your consent to participate at any time. You have been given a copy of this agreement.

You have been told that by signing this consent agreement you are not giving up any of your legal rights.

Name of Participant (please print)

Signature of Participant Date

Signature of Investigator

Date

Please indicate with a signature below if you give your consent to have this interview audio taped: 
Name of Participant (please print)

Signature of Participant

Date

Signature of Investigator

Date

Please indicate with your signature below if you give your consent to be contacted regarding the study results:

Name of Participant (please print)

Signature of Participant

Date

Signature of Investigator

Date 